Revista Geográfica Digital. IGUNNE. Facultad de Humanidades. UNNE. Año 14. № 27.

Enero - Junio 2017. ISSN 1668-5180 Resistencia, Chaco

\title{
USO DE MEDICIONES DE ALTA FRECUENCIA PARA EL ANÁLISIS DE EVENTOS METEOROLÓGICOS URBANOS
}

\author{
Dr. Federico Ferrelli ${ }^{1}$ y Dra. María Cintia Piccolo ${ }^{1,2}$ \\ 1 Instituto Argentino de Oceanografía, Consejo Nacional de \\ Investigaciones Científicas y Técnicas (IADO-CONICET). \\ Florida 8000. Complejo CCT CONICET, Edificio E1. B8000FWB Bahía \\ Blanca, Buenos Aires, Argentina. \\ ${ }^{2}$ Departamento de Geografía y Turismo, Universidad Nacional del Sur. \\ 12 de octubre y San Juan, 4ํㅜ piso, B8000FWB Bahía Blanca, Buenos \\ Aires, Argentina. \\ Autor de contacto: fferrelli@criba.edu.ar
}

\begin{abstract}
Resumen
Los estudios de eventos meteorológicos urbanos permiten obtener información útil para diseñar planes de manejo del territorio. Ciertos eventos meteorológicos que no necesariamente son extremos afectan a la población, al arbolado urbano, a la infraestructura edilicia, al confort del habitante, etc. En este contexto, el objetivo de este trabajo fue estudiar los impactos de distintos eventos meteorológicos urbanos a escala local y micro-local en la ciudad de Bahía Blanca, Argentina. Para ello, se diseñaron e instalaron diez estaciones meteorológicas que registraron información en alta frecuencia en distintos vecindarios de la ciudad. Se identificaron eventos de vientos fuertes del norte y del sur, olas de calor, olas de frío, chubascos, nieblas y heladas. La relevancia de analizar las variaciones térmicas y de la humedad relativa en alta frecuencia es que permitieron identificar que las diferencias propias del paisaje urbano manifestaron comportamientos particulares. Las distintas coberturas del suelo determinadas por la cantidad de arbolado urbano, calles pavimentadas, parques y plazas definieron comportamientos meteorológicos diferentes a escala micro-local. Los resultados de esta investigación representan información indispensable para orientar los futuros planes de manejo del espacio urbano.
\end{abstract}

Palabras clave. Eventos meteorológicos urbanos, alta frecuencia, escala local y micro-local.

UTILIZATION OF HIGH FREQUENCY DATA FOR ANALYZING URBAN METEOROLOGICAL EVENTS

\section{Abstract}

The occurrence of urban meteorological events could affect the health of the population, the development of urban trees and the state of buildings. In these contexts, the aim of this work was to study the impacts of different urban meteorological events in a local and micro-local

Publicado en formato digital: Dr. Federico Ferrelli y Dra. María Cintia Piccolo. USO DE MEDICIONES DE ALTA FRECUENCIA PARA EL ANÁLISIS DE EVENTOS METEOROLÓGICOS URBANOS. Revista Geográfica Digital. IGUNNE. Facultad de Humanidades. UNNE. Año 14. № 27. Enero - Junio 2017. ISSN 1668-5180 Resistencia, Chaco.

En: http://hum.unne.edu.ar/revistas/geoweb/default.htm1 
Revista Geográfica Digital. IGUNNE. Facultad de Humanidades. UNNE. Año 14. № 27.

Enero - Junio 2017. ISSN 1668-5180 Resistencia, Chaco

scale in Bahia Blanca city (Argentina). To do this, it was designed ten meteorological stations that registered high frequency data. These were located in different neighborhoods. Subsequently, there were identified strong winds from the north and south, heat and cold waves, heavy rains, frost and fogs. The importance of analyzing meteorological variations with high frequency data is the possibility of determining differences in the urban landscape, which expressed a particular thermal and relative humidity pattern. Urban land covers varied according to the amount of urban trees, paved street, parks and squares. Results of this study allowed to generate useful information for the future urban plans.

Key words. Urban meteorological events, high frequency data, local and micro-local analyses.

\section{Introducción}

Las ciudades generan cambios en la atmósfera local, ocasionando un clima que difiere de las condiciones naturales de su entorno. De todas las modificaciones que se encuentran en las urbanizaciones, los cambios térmicos son los más conocidos por sus habitantes (Fuentes Pérez, 2014). Las variaciones de los distintos parámetros meteorológicos se atenúan en las ciudades debido a los cambios del paisaje. Las diferencias estructurales del espacio urbano a escala micro-local modifican el comportamiento térmico, de la humedad relativa y del viento. Estos parámetros meteorológicos varían en primera instancia según el tamaño de la ciudad (Oke, 1973), según el tipo de construcciones y la distancia entre las mismas (Szegedi y Kircsi, 2003), según los materiales que los componen (Correa et al., 2003), según la cantidad de calor antrópico generado por las actividades humanas per se y según la topografía urbana (Stewart y Oke, 2012; Coronel et al., 2014).

Los centros urbanos están en constante crecimiento, lo que modifica las condiciones atmosféricas locales debido al aumento de la emisión de los gases de efecto invernadero, causantes del incremento de la temperatura. El calentamiento de las ciudades es heterogéneo y está determinado por la calidad y cantidad de la infraestructura urbana (Hardoy y Pandiella, 2007; Barton et al., 2009). Los efectos de la variabilidad climática se observan con el aumento de la frecuencia e intensidad de eventos meteorológicos naturales. Los mismos afectan a la calidad de vida, a las actividades económicas y el acceso a bienes y servicios (Santiago Lastra et al., 2008).

Las olas de calor, las olas de frío, las lluvias intensas, heladas, etc., tienen impactos diversos sobre el ambiente urbano. Por ejemplo, los eventos extremos de temperatura afectan a la salud de la población generando problemas respiratorios, cardiovasculares e incluso la muerte (Alberdi et al., 1998; García Palomares y Alberdi, 2005; García-Pina et al., 2008). Por otro lado, las lluvias intensas generan anegamientos en zonas frágiles, las heladas afectan a la vegetación urbana y se pueden seguir enumerando las consecuencias de eventos meteorológicos naturales sobre el paisaje urbano. Además, y como consecuencia de todos estos fenómenos, se generan impactos sobre la infraestructura urbana (Cogliati et al., 2006; Hardoy y Pandiella, 2007; Zapperi, 2014; Reguero et al.,2015).

Publicado en formato digital: Dr. Federico Ferrelli y Dra. María Cintia Piccolo. USO DE MEDICIONES DE ALTA FRECUENCIA PARA EL ANÁLISIS DE EVENTOS METEOROLÓGICOS URBANOS. Revista Geográfica Digital. IGUNNE. Facultad de Humanidades. UNNE. Año 14. № 27. Enero - Junio 2017. ISSN 1668-5180 Resistencia, Chaco.

En: http://hum.unne.edu.ar/revistas/geoweb/default.htm2 
Considerando que los eventos meteorológicos impactan de forma diferente en la distribución espacial de la temperatura y la humedad relativa urbana, el objetivo de este estudio fue analizar con mediciones de alta frecuencia las variaciones térmicas y de la humedad relativa en distintos vecindarios de la ciudad de Bahía Blanca (Argentina) para instrumentar planes de manejo y desarrollo urbano.

\section{2. Área de estudio}

La ciudad de Bahía Blanca está localizada en el sudoeste de la provincia de Buenos Aires (Argentina) en el partido homónimo (38 $35^{\prime}$ Sur, 62 13' Oeste) (Figura 1). Los valores altimétricos de la ciudad oscilan entre los 8 y los $74 \mathrm{msnm}$. La altitud va descendiendo en sentido norte-sur. Los barrios del norte de la ciudad se localizan en un nivel de terraza que supera los $60 \mathrm{msnm}$. En general el trazado de su plano es en forma de damero interrumpido en ciertas ocasiones por la altura del terreno.

La ciudad presenta una temperatura media anual de $15,5^{\circ} \mathrm{C}$ y una precipitación media anual de $654 \mathrm{~mm}$. Los vientos dominantes son del cuadrante norte, noroeste y oeste, con velocidades medias máximas de $70 \mathrm{~km} \mathrm{~h}^{-1}$ (Servicio Meteorológico Nacional (SMN), Argentina, 2014). Dentro del ejido urbano se extiende el Arroyo Napostá Grande. El sector norte se caracteriza por presentar áreas ajardinadas en torno a su cauce y aguas abajo se ha entubado. También se emplaza el canal Maldonado que actúa como derivador de aguas en las épocas de crecidas del Napostá Grande y se extiende a cielo abierto a lo largo del sector occidental de la ciudad (Capelli de Steffens et al., 2005).

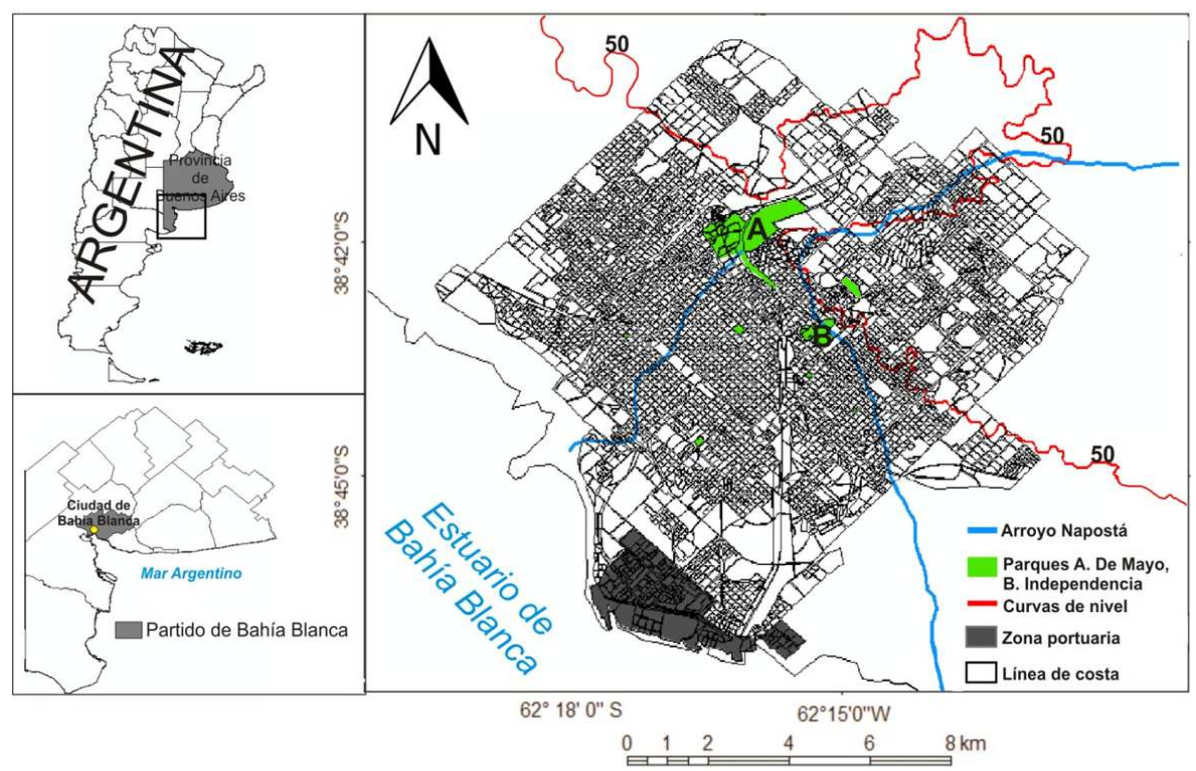

Figura 1. Localización de la ciudad de Bahía Blanca.

El arbolado urbano es discontinuo y en ciertas arterias, inexistente. En la ciudad se localizan dos parques: el Parque Independencia y el Parque de Mayo, ambos con abundante vegetación de tipo arbóreo (Figura 1). Las costas del estuario ubicado al sur de la ciudad

Publicado en formato digital: Dr. Federico Ferrelli y Dra. María Cintia Piccolo. USO DE MEDICIONES DE ALTA FRECUENCIA PARA EL ANÁLISIS DE EVENTOS METEOROLÓGICOS URBANOS. Revista Geográfica Digital. IGUNNE. Facultad de Humanidades. UNNE. Año 14. № 27. Enero - Junio 2017. ISSN 1668-5180 Resistencia, Chaco.

En: http://hum.unne.edu.ar/revistas/geoweb/default.htm3 
presentan suelos salinos con vegetación de halófitas. El principal parque industrial y el puerto de la ciudad se emplazan sobre la costa de este estuario. Cuando el viento sopla de principalmente del sector Norte se originan vórtices y torbellinos en la ciudad de acuerdo a la forma y orientación de los edificios (Capelli de Steffens et al., 2005). La ausencia de vegetación altera la distribución espacial de la humedad relativa y la energía que desprenden los edificios durante la noche ocasiona una fuente artificial de calor que da como resultado la formación de islas de calor (Capelli de Steffens et al., 2005). La población en el año 2010 era de 301.531 habitantes (INDEC, 2010). La ciudad adquiere relevancia regional ya que es el segundo centro portuario más importante de Argentina.

\section{Metodología}

Para estudiar los diferentes condiciones meteorológicas de la ciudad a escala micro-local se instalaron diez estaciones, que registraron información de temperatura y humedad en distintos barrios de la ciudad. La localización de las estaciones se eligió para que representasen distintas condiciones de sitio como el centro de la ciudad, la zona costera, los parques, periferia, etc. (Figura 2 y Tabla 1). El período de medición abarcó desde el 1 de octubre de 2013 hasta el 8 de diciembre de 2014. La frecuencia de los registros fue de 30 minutos. La estación localizada en el extremo norte estuvo equipada además con sensores que registraron datos de velocidad de viento, radiación solar, presión atmosférica y precipitación (también cada 30 minutos). Con esta información se establecieron períodos en los que ocurrieron distintos eventos meteorológicos en la ciudad. Posteriormente se analizó la distribución espacial de la temperatura media, máxima o mínima durante cada evento. Además, se estudiaron las anomalías de temperatura y humedad relativa durante estos eventos a escala micro-local para finalmente describir los impactos observados sobre el ambiente urbano.

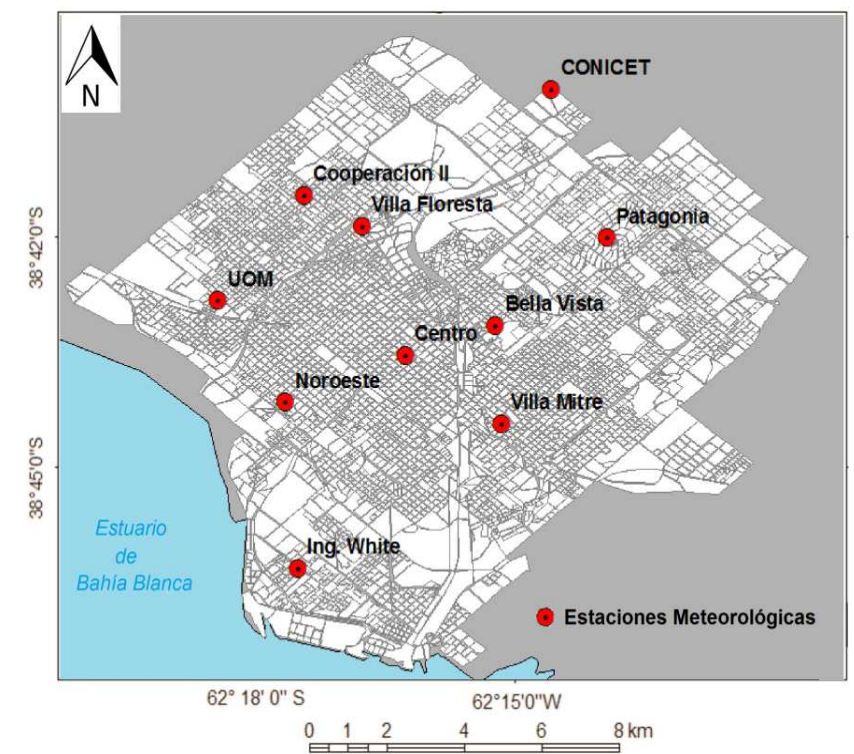

Figura 2. Localización de las estaciones meteorológicas.

Publicado en formato digital: Dr. Federico Ferrelli y Dra. María Cintia Piccolo. USO DE MEDICIONES DE ALTA FRECUENCIA PARA EL ANÁLISIS DE EVENTOS METEOROLÓGICOS URBANOS. Revista Geográfica Digital. IGUNNE. Facultad de Humanidades. UNNE. Año 14. № 27. Enero - Junio 2017. ISSN 1668-5180 Resistencia, Chaco.

En: http://hum.unne.edu.ar/revistas/geoweb/default.htm4 
Las estaciones estuvieron constituidas por una caja plástica que recubrió los sensores junto con una fuente de alimentación de energía (pilas). En la parte inferior se localizó una red plástica que contuvo los sensores y permitió la circulación del aire. Al lado de ésta se incorporó un adaptador que permitió conectarlas con una computadora portátil. De esta forma, se descargaron los datos mensualmente y luego se reiniciaban las mediciones, dado que cada dispositivo tenía una capacidad de almacenamiento limitada $(500 \mathrm{Mb})$. Todas las estaciones se localizaron en sitios con similares condiciones: al resguardo de las precipitaciones, a la sombra y a $2 \mathrm{~m}$ de altura.

\begin{tabular}{|c|c|c|}
\hline Estación & Nombre & Características de la localización \\
\hline 1 & CONICET & $\begin{array}{l}\text { Localizada en el extremo norte de la ciudad. Zona con } \\
\text { mayor altura y menor densidad de edificaciones. } \\
\text { Representó un área periurbana-rural durante el } \\
\text { período de las mediciones. Es la estación con más } \\
\text { cantidad de sensores. }\end{array}$ \\
\hline 2 & Patagonia & $\begin{array}{l}\text { Barrio parque con abundante arbolado urbano y } \\
\text { espacios verdes. }\end{array}$ \\
\hline 3 & Bella Vista & Representativa del Parque Independencia. \\
\hline 4 & Villa Floresta & $\begin{array}{l}\text { Localizada en las proximidades del Parque de Mayo; } \\
\text { representa un área de construcciones abundantes } \\
\text { pero de escasa altura }\end{array}$ \\
\hline 5 & Cooperación II & $\begin{array}{l}\text { Es un barrio residencial con edificaciones de baja } \\
\text { altura y con presencia de terrenos al descubierto. }\end{array}$ \\
\hline 6 & UOM & $\begin{array}{l}\text { Presenta las mismas características que Cooperación } \\
\text { II pero tiene mayor cantidad de calles sin pavimentar }\end{array}$ \\
\hline 7 & Centro & $\begin{array}{l}\text { Es el centro de la ciudad. Presenta la mayor densidad } \\
\text { edilicia con edificios elevados, la menor cantidad de } \\
\text { arbolado urbano y espacios verdes }\end{array}$ \\
\hline 8 & Villa Mitre & $\begin{array}{l}\text { Es un barrio con similares características al centro } \\
\text { pero con menor cantidad de edificios elevados. Las } \\
\text { edificaciones son densas y los espacios verdes } \\
\text { dispersos. }\end{array}$ \\
\hline 9 & Noroeste & $\begin{array}{l}\text { Barrio residencial próximo a las costas del estuario de } \\
\text { Bahía Blanca. }\end{array}$ \\
\hline 10 & $\begin{array}{l}\text { Ingeniero } \\
\text { White }\end{array}$ & $\begin{array}{l}\text { Representativo de las condiciones costeras. } \\
\text { Representó al puerto de la ciudad. }\end{array}$ \\
\hline
\end{tabular}

Tabla 1. Caracterización de la localización de cada estación meteorológica.

Publicado en formato digital: Dr. Federico Ferrelli y Dra. María Cintia Piccolo. USO DE MEDICIONES DE ALTA FRECUENCIA PARA EL ANÁLISIS DE EVENTOS METEOROLÓGICOS URBANOS. Revista Geográfica Digital. IGUNNE. Facultad de Humanidades. UNNE. Año 14. № 27. Enero - Junio 2017. ISSN 1668-5180 Resistencia, Chaco. 
Revista Geográfica Digital. IGUNNE. Facultad de Humanidades. UNNE. Año 14. № 27.

Enero - Junio 2017. ISSN 1668-5180 Resistencia, Chaco

Los eventos meteorológicos observados fueron:

Vientos fuertes del norte y del sur. El viento es un factor importante para el estudio de la isla de calor en las ciudades (ICU). Se definió una velocidad crítica por encima de la cual no se generaría la ICU (Oke y Hannell, 1970). Para la ciudad de Bahía Blanca esa velocidad es de $30,2 \mathrm{~km} \mathrm{~h}^{-1}$. Se consideraron dos eventos por presentar características diferentes: vientos provenientes del norte (cálido y seco) y del sur (húmedo y frío).

Olas de calor. Es un estado de tiempo atmosférico que se caracteriza por presentar elevadas temperaturas y humedad relativa. Su extensión e intensidad son diversas y habitualmente presentan una duración aproximadamente semanal (Capelli de Steffens et al., 2001). En Argentina este fenómeno es una amenaza natural y frecuente (Piccolo y Capelli de Steffens, 1985).

Olas de frío. Este evento junto con la ola de calor se caracteriza por presentar una alteración del ritmo térmico considerado como normal, presentando temperaturas inferiores al mismo. En general presentan efectos negativos para la población, la agricultura, la ganadería y el medio natural (Cuadrat et al., 2014).

Chubascos o lluvias torrenciales. Los chubascos se caracterizan por ser un tipo de precipitación abundante de gran intensidad y de corta duración. En general impactan sobre un área reducida dado que se generan en su mayoría por una corriente convectiva de aire y normalmente van acompañadas por actividad eléctrica (SMN, 1989; OMM, 1992; García, 2014).

Heladas. Las heladas son fenómenos meteorológicos que ocurren cuando la temperatura del aire es igual o menor a $0 \stackrel{\circ}{\circ}$. Estas afectan a las actividades económicas, a la vegetación urbana y a las actividades al aire libre dado que generan en muchos casos sensación de disconfort por enfriamiento (Seluchi, 1992; Müller, 2005; Cogliati et al., 2006).

Nieblas. Son los eventos conocidos como precipitaciones indirectas. Se originan principalmente por la presencia de vapor de agua en superficie proveniente de los espacios verdes o sistemas sinópticos en zonas costeras (Barradas, 1983). Se presentan cuando la humedad relativa es mayor al $95 \%$ durante un período de tiempo prolongado y su duración puede abarcar varias horas e incluso días (Pejenaute Goñi, 2006).

Estos eventos se identificaron a partir del análisis de las mediciones provenientes de la estación localizada al norte de la ciudad (CONICET, Figura 2) y de la observación y análisis de mapas sinópticos provistos por Servicio Meteorológico Nacional (SMN, Argentina). Se analizaron los datos de la temperatura del aire, velocidad y dirección del viento, humedad relativa y presión atmosférica. Con ello se identificaron: Vientos intensos del norte (22 de noviembre de 2013) y del sur (12 de abril de 2014); Olas de calor de verano (17 al 19 de enero de 2014) y de invierno (17 al 20 de agosto de 2014); Olas de frío en verano (25 al 27 de febrero de 2014), Heladas (26 y 27 de julio de 2014), Chubascos (24 de octubre de 2014) y Nieblas (5 y 6 de julio de 2014).

El análisis de los eventos se realizó en dos escalas. Primero se determinó la distribución espacial de la temperatura y la humedad relativa media de cada evento considerando la información obtenida en las estaciones meteorológicas (Figura 2). Además se analizó la distribución espacial de ambos parámetros durante el horario de la máxima temperatura en olas de calor, a la hora de la mínima temperatura en la ola de frío, la máxima ráfaga en los eventos de vientos intensos tanto del norte como del sur y se establecieron las áreas en donde se

Publicado en formato digital: Dr. Federico Ferrelli y Dra. María Cintia Piccolo. USO DE MEDICIONES DE ALTA FRECUENCIA PARA EL ANÁLISIS DE EVENTOS METEOROLÓGICOS URBANOS. Revista Geográfica Digital. IGUNNE. Facultad de Humanidades. UNNE. Año 14. № 27. Enero - Junio 2017. ISSN 1668-5180 Resistencia, Chaco.

En: http://hum.unne.edu.ar/revistas/geoweb/default.htm6 
Revista Geográfica Digital. IGUNNE. Facultad de Humanidades. UNNE. Año 14. № 27.

Enero - Junio 2017. ISSN 1668-5180 Resistencia, Chaco

presentaron heladas y nieblas. Para ello se consideraron los valores de temperatura del aire menor o igual a $0 \stackrel{\circ}{\circ}$ para las primeras y los valores de humedad relativa superiores a $95 \%$ para las segundas. La representación espacial de los resultados se realizó con el Software ArcGIS 9.3 mediante el método de interpolación Kriging Ordinario de tipo esférico.

Se completó el estudio estableciendo distintos umbrales de temperatura y humedad relativa. Al no haber un criterio uniforme para la definición de las olas de calor y las de frío, en general algunos autores proponen relacionar el período térmico del evento con un umbral determinado (Prieto et al., 2004; Díaz et al., 2005; Cony et al., 2008 y 2010; Cuadrat et al., 2014). En este estudio se determinaron los siguientes umbrales: valores medios mensuales y diarios (día anterior y posterior al desarrollo de cada evento). Se calculó la diferencia entre los valores medios de todos los eventos con dichos umbrales. Estos se consideraron como anomalías entre la temperatura y la humedad relativa medias (diaria o mensual) y la registrada durante los distintos eventos meteorológicos. Esta escala permitió estudiar los impactos y la intensidad de los distintos eventos en los diferentes vecindarios de la ciudad.

\section{Resultados}

\subsection{Análisis de los eventos urbanos a escala local}

En las próximas secciones se presentan de forma separada los resultados obtenidos para cada uno de los eventos urbanos analizados. Los mismos se estudiaron considerando su distribución térmica y de humedad relativa y sus anomalías. En el caso particular de las nieblas y las heladas se delimitaron las aquellas zonas en donde este evento se manifestó.

\subsubsection{Vientos intensos del norte y del sur}

Los vientos son importantes para caracterizar el clima de las ciudades costeras. Se prevé que en las últimas décadas los mismos serán más intensos y estarán asociados a tormentas severas que podrían dañar la infraestructura urbana y generar en algunos casos posibles inundaciones (Reguero et al., 2015). Las zonas con edificios de gran altura interrumpen el desplazamiento de los vientos generando que los contaminantes no puedan dispersarse de la misma manera que en aquellos sectores en los que las edificaciones tienen menor altura. Esto es así porque se generan torbellinos en torno a los edificios que impiden la circulación del viento (Llanque Chana, 2003).

Como ejemplo se menciona lo ocurrido el 22 de noviembre de 2013, donde soplaron vientos del sector norte en la ciudad de Bahía Blanca. La situación sinóptica de ese día estuvo caracterizada por un centro de alta presión (1030 hPa) sobre las costas de la provincia de Buenos Aires que generó la circulación de vientos del norte (Figura 3). Hubo nubosidad debido a una situación de frente frío al sur del área de estudio. La velocidad media del viento fue de 19 $\mathrm{km} \mathrm{h}^{-1}$, con un promedio de las ráfagas de $43 \mathrm{~km} \mathrm{~h}^{-1}$. La dirección predominante del viento fue NNW $(47,9 \%)$ y en menor medida NW (33,4\%). Las calmas $(6 \%)$ se presentaron desde las 00:30 hasta las 2:00. La presión atmosférica diaria fue $1004 \mathrm{hPa}$ y la ráfaga máxima se presentó a las 14:30 horas con una velocidad de $68 \mathrm{~km} \mathrm{~h}^{-1}$.

Publicado en formato digital: Dr. Federico Ferrelli y Dra. María Cintia Piccolo. USO DE MEDICIONES DE ALTA FRECUENCIA PARA EL ANÁLISIS DE EVENTOS METEOROLÓGICOS URBANOS. Revista Geográfica Digital. IGUNNE. Facultad de Humanidades. UNNE. Año 14. № 27. Enero - Junio 2017. ISSN 1668-5180 Resistencia, Chaco.

En: http://hum.unne.edu.ar/revistas/geoweb/default.htm7 


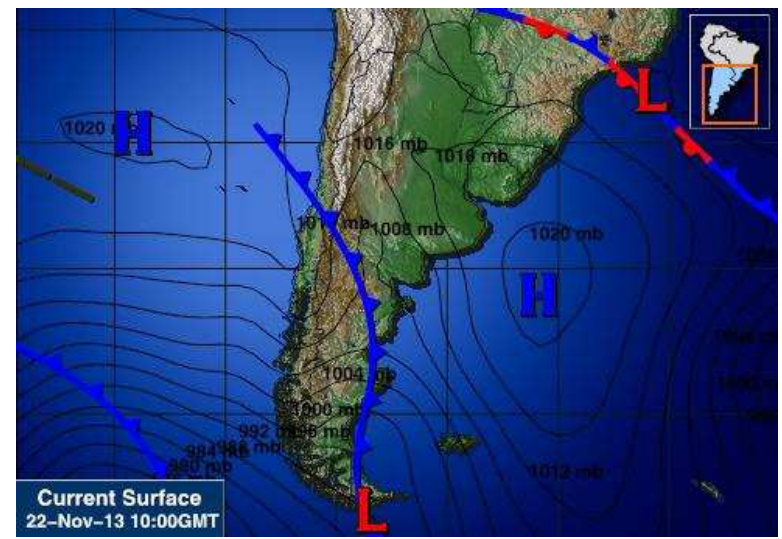

Figura 3. Situación sinóptica del día 22 de noviembre de 2013. Fuente: www.intellicast.com

La distribución espacial de la temperatura media del aire estuvo relacionada con la dirección del viento. Las áreas calientes se extendieron en sentido noroeste-sudeste y las frías en el sudoeste y el sur. La humedad relativa presentó una situación similar. Los menores valores se registraron en el noroeste y se incrementaron hacia el sudeste (Figura 4). Esta situación permite afirmar que los vientos tienen un fuerte impacto en ambos parámetros dado que al ser cálidos, secos y fuertes durante este ${ }^{-1-}$ modificaron la distribución espacial de ambos parámetros. La intensidad de la isla de ca $A$ ICU) fue $4,1^{\circ} \mathrm{C}$ y la diferencia espacial urbana de la humedad de $21 \%$. Una situación simılar se presentó al analizar la distribución de ambos parámetros durante la máxima ráfaga, donde la IICU fue $5,3 \stackrel{\circ}{\mathrm{C}}$ (Figura 4).
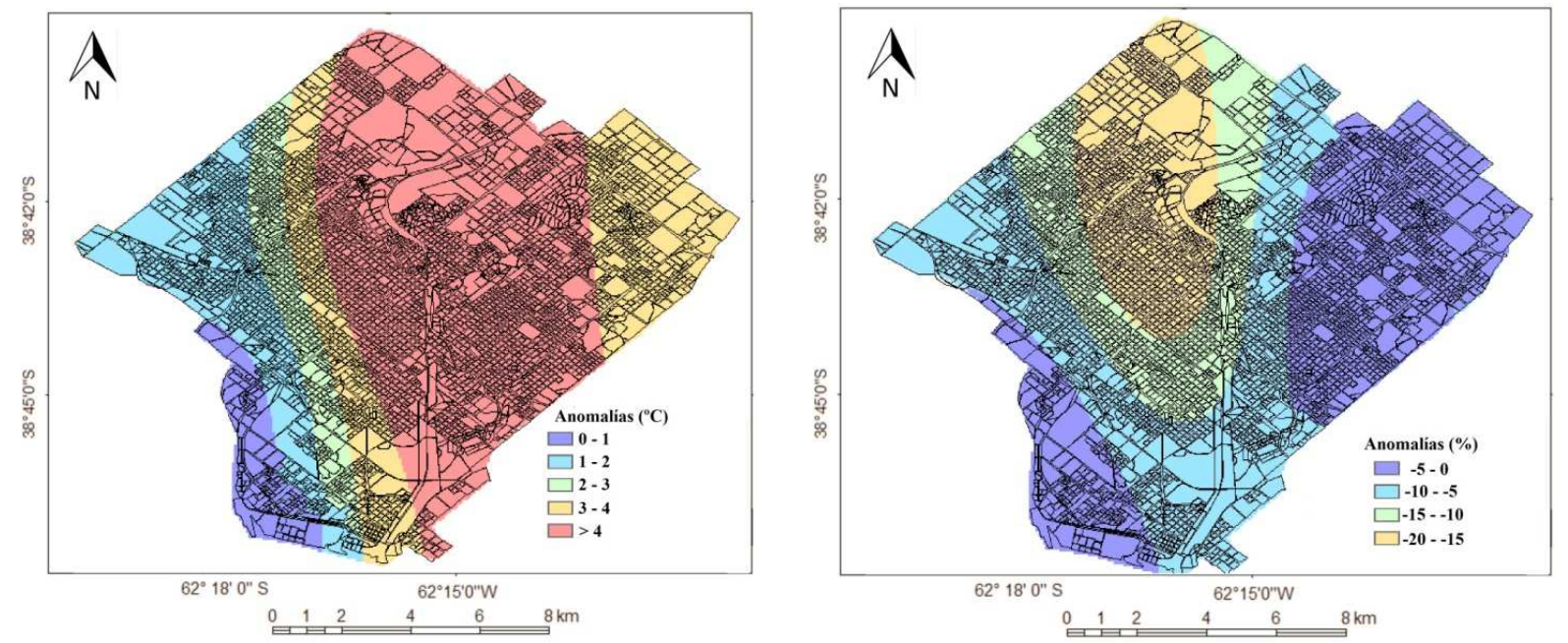

Figura 4. Anomalías de la temperatura (A) y la humedad relativa (B) media diaria del día 22 de noviembre de 2013.

Publicado en formato digital: Dr. Federico Ferrelli y Dra. María Cintia Piccolo. USO DE MEDICIONES DE ALTA FRECUENCIA PARA EL ANÁLISIS DE EVENTOS METEOROLÓGICOS URBANOS. Revista Geográfica Digital. IGUNNE. Facultad de Humanidades. UNNE. Año 14. № 27. Enero - Junio 2017. ISSN 1668-5180 Resistencia, Chaco.

En: http://hum.unne.edu.ar/revistas/geoweb/default.htm8 
Por otro lado, el 12 de abril de 2014 soplaron vientos del sur sobre la ciudad de Bahía Blanca. En este día, la situación sinóptica indicó la presencia de dos centros de baja presión. Uno localizado en las costas de la provincia de Buenos Aires (1002 hPa) y otro sobre las costas de Uruguay (1008 hPa) (Figura 5). Esta situación generó vientos fuertes del sur y sudoeste. La ráfaga máxima del día se presentó a las $18 \mathrm{hs}$ con una velocidad de $66 \mathrm{~km} \mathrm{~h}^{-1}$. Durante este evento la nubosidad fue variable. La presión atmosférica media diaria fue $1009 \mathrm{hPa}$. El viento predominante fue del SE (92\%) y en menor medida del W $(8 \%)$ y no se registraron calmas.

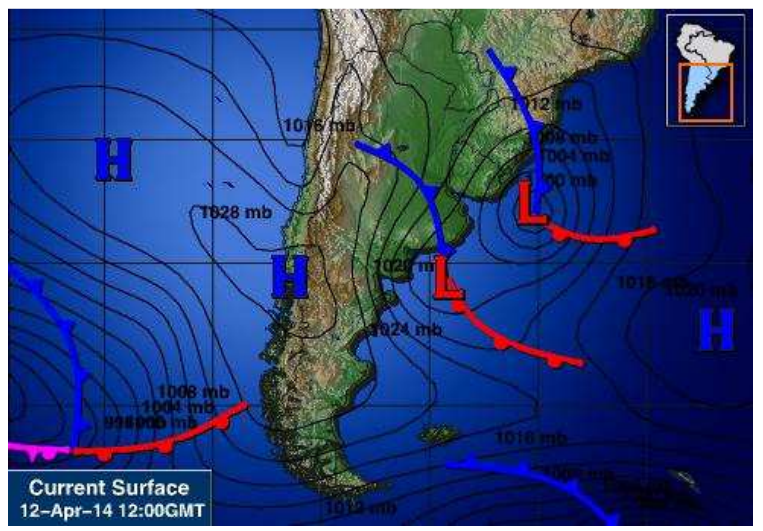

Figura 5. Situación sinóptica del día 12 de abril de 2014. Fuente: www.intellicast.com

Se calcularon anomalías de temperatura y resultaron negativas. Estas fueron mayores en el centro de la ciudad y menores en la periferia. La zona costera tuvo valores intermedios (con datos comprendidos entre los máximos y los mínimos) y el noroeste presentó los menores registros. La intensidad de la isla de calor fue $5 \stackrel{\circ}{\circ}$ y la diferencia espacial de la humedad $16 \%$ (Figura 6). Se observó que al horario de la máxima ráfaga los mayores valores de humedad relativa se localizaron en el centro y centro-oeste del núcleo urbano. En ambas situaciones la ciudad fue más húmeda que su periferia. 

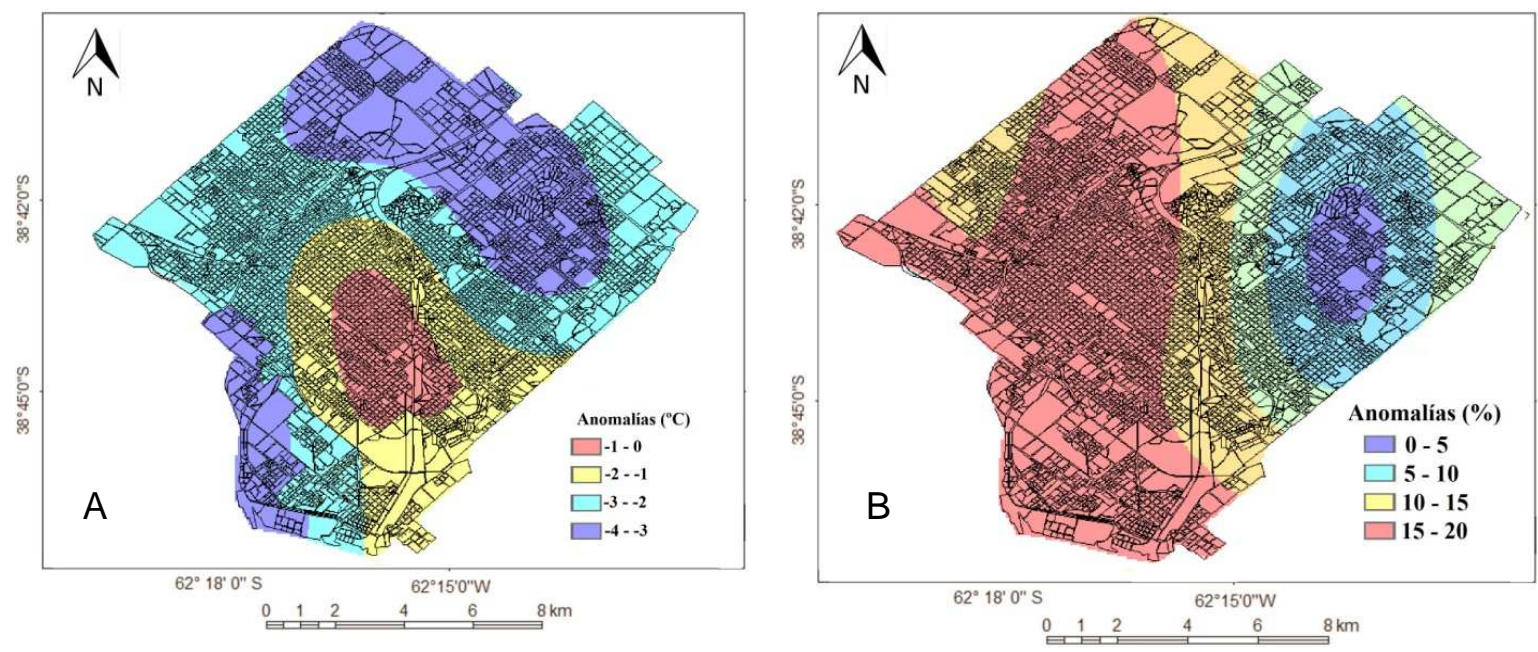

Figura 6. Anomalías de la temperatura (A) y la humedad relativa (B) media diaria del día 12 de

\subsubsection{Olas de calor} abril de 2014.

Las olas de calor tienen un impacto negativo sobre la salud de la población. Durante estos eventos se intensifica el desconfort y pueden generar complicaciones graves en la salud de aquellas personas que sufren problemas cardiovasculares, respiratorios, renales y obesidad. Por ello, es necesario tener un sistema de protección para prevenir los efectos adversos de estos eventos extremos (Villamil Cajoto et al., 2005).

En el período de estudio se identificó una ola de calor estival los días 17, 18 y 19 de enero de 2014. Una línea de inestabilidad ( $1002 \mathrm{hPa}$ ) se desplazó sobre la ciudad el 17 de enero. En los días subsiguientes las condiciones de escaso viento o viento suave del norte generado por un sistema de alta presión representaron las condiciones sinópticas de la ciudad (Figura 7). Durante este evento predominaron las calmas. La velocidad media del viento fue de $9 \mathrm{~km} \mathrm{~h}^{-1}$ provenientes del E-SE y NW. Las temperaturas medias fueron $31,5{ }^{\circ} \mathrm{C}, 27,7{ }^{\circ} \mathrm{C}$ y $28,8{ }^{\circ} \mathrm{C}$ los días 17, 18 y 19 de enero, respectivamente. Las máximas temperaturas alcanzaron los $40{ }^{\circ} \mathrm{C}$ (17 de enero, desde 14:00-15:00 hs), $37,8 \stackrel{\circ}{\circ}$ (18 de enero, 13:00-14:00 hs) y 39,1 ${ }^{\circ} \mathrm{C}$ (19 de enero, 17:00-18:00 hs). Durante este evento el aumento de la temperatura en la ciudad fue de $6 \stackrel{\circ}{\mathrm{C}}$.

Publicado en formato digital: Dr. Federico Ferrelli y Dra. María Cintia Piccolo. USO DE MEDICIONES DE ALTA FRECUENCIA PARA EL ANÁLISIS DE EVENTOS METEOROLÓGICOS URBANOS. Revista Geográfica Digital. IGUNNE. Facultad de Humanidades. UNNE. Año 14. № 27. Enero - Junio 2017. ISSN 1668-5180 Resistencia, Chaco.

En: http://hum.unne.edu.ar/revistas/geoweb/default.htm10 

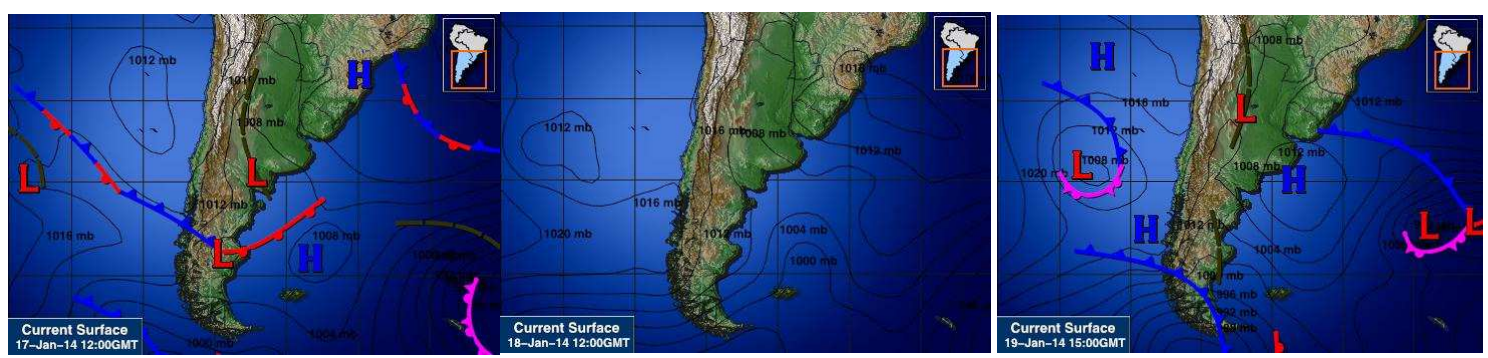

Figura 7. Situación sinóptica del 18 y 19 de enero de 2014. Fuente: www.intellicast.com

La zona urbana más cálida se extendió con una dirección norte-sur. La máxima temperatura media diaria fue $31,2{ }^{\circ} \mathrm{C}$ en Villa Mitre. Las mínimas (en Ing. White y CONICET) fueron $28,8 \stackrel{\circ}{\circ}$ y se localizaron en la periferia de la ciudad. La humedad relativa fue menor en aquellos lugares en donde la temperatura fue mayor (Figura 8). Considerando los valores medios, la IICU fue $2,4{ }^{\circ} \mathrm{C}$ y hubo una escasa diferencia espacial de la humedad (12\%), presentándose una ciudad más seca que su periferia.

Durante la máxima temperatura, se observó que la periferia del noroeste y oeste fueron más cálidas que el resto de la ciudad. Las temperaturas intermedias se presentaron en el centro noreste, definiendo un área cálida. Las menores temperaturas se midieron en el centro de la ciudad y la zona portuaria. La humedad relativa fue mayor en el centro urbano. Los registros intermedios se presentaron en la zona costera y el noreste y los menores en el noroeste y oeste. La intensidad de la isla de calor fue $4,2{ }^{\circ} \mathrm{C}$ y la diferencia espacial de la humedad fue también muy pequeña $(7 \%)$, presentando un centro urbano más húmedo que su periferia.

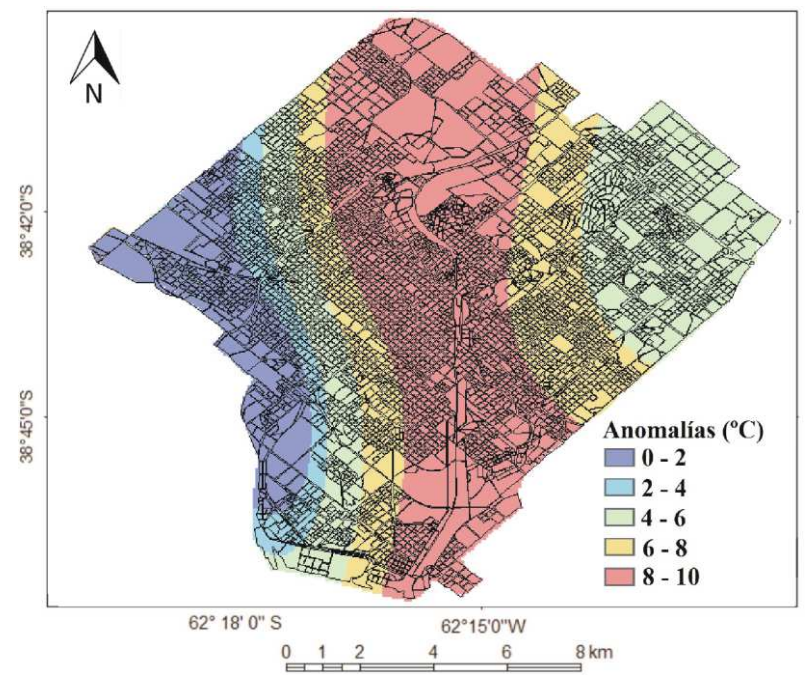

Figura 8. Anomalías de temperatura durante la ola de calor estival.

Publicado en formato digital: Dr. Federico Ferrelli y Dra. María Cintia Piccolo. USO DE MEDICIONES DE ALTA FRECUENCIA PARA EL ANÁLISIS DE EVENTOS METEOROLÓGICOS URBANOS. Revista Geográfica Digital. IGUNNE. Facultad de Humanidades. UNNE. Año 14. № 27. Enero - Junio 2017. ISSN 1668-5180 Resistencia, Chaco.

En: http://hum.unne.edu.ar/revistas/geoweb/default.htm11 
En la estación invernal se registró otro evento de ola de calor. Este se extendió desde el 17 al 20 de agosto de 2014. La situación sinóptica del 17 de agosto estuvo caracterizada por la acción de dos Anticiclones localizados en los océanos Atlántico y Pacífico, luego una línea de inestabilidad se convirtió en un frente estacionario. Esta situación generó en la ciudad de Bahía Blanca vientos del oeste de escasa velocidad y escasa nubosidad. Esta situación fue similar el 18 de agosto. El 19 se caracterizó por la presencia de un frente estacionario y se observó un centro de alta presión en el sur de la región donde se localiza la ciudad. El 20 de agosto el centro de alta presión del Océano Atlántico generó una circulación del norte (Figura 9). La temperatura urbana durante este evento se incrementó 3,6 ํㅡ.
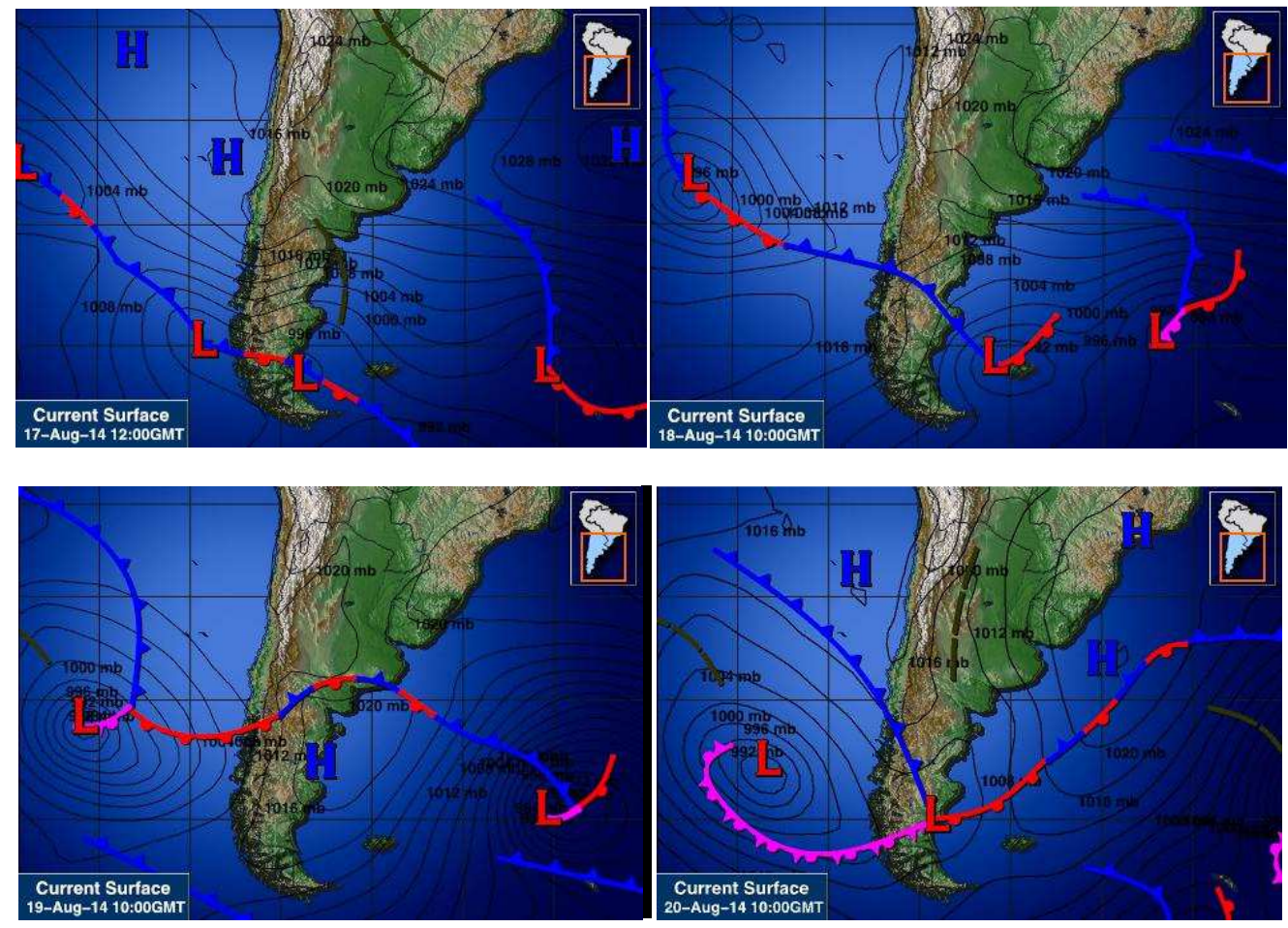

Figura 9. Situación sinóptica de los días 19 y 20 de agosto de 2014. Fuente:

www.intellicast.com

La velocidad media del viento fue $13 \mathrm{~km} \mathrm{~h}^{-1}$ con direcciones que rotaron desde el $\mathrm{E}$ al NW. La temperatura media del evento fue $17,9{ }^{\circ} \mathrm{C}$ y la máxima $27,2{ }^{\circ} \mathrm{C}$. La presión atmosférica fue normal $(1012,8 \mathrm{hPa})$, oscilando entre 1006 y $1016 \mathrm{hPa}$ y no se observaron nubes.

La distribución espacial de la temperatura urbana presentó un área cálida que se extendió en sentido oeste-este (Figura 10). Las menores temperaturas se midieron en la periferia del

Publicado en formato digital: Dr. Federico Ferrelli y Dra. María Cintia Piccolo. USO DE MEDICIONES DE ALTA FRECUENCIA PARA EL ANÁLISIS DE EVENTOS METEOROLÓGICOS URBANOS. Revista Geográfica Digital. IGUNNE. Facultad de Humanidades. UNNE. Año 14. № 27. Enero - Junio 2017. ISSN 1668-5180 Resistencia, Chaco.

En: http://hum.unne.edu.ar/revistas/geoweb/default.htm12 
norte, noroeste, noreste y la zona costera. La máxima temperatura media fue $21,1 \stackrel{\circ}{ } \mathrm{C}$ (Villa Mitre) y la mínima $17,9 \stackrel{\circ}{\circ}$ (Ing. White), marcando una IICU de 3,2 ${ }^{\circ} \mathrm{C}$. Las anomalías térmicas permitieron establecer una relación con el evento estival, exceptuando el oeste de la ciudad que fue más cálido durante la estación invernal. La humedad relativa fue mayor en el noreste y sur y menor en el centro, este y oeste de la ciudad. La diferencia espacial de este parámetro fue $26 \%$.

A la hora de la máxima temperatura registrada durante este evento se observó una lengua cálida que se extendió desde el oeste, hacia el barrio de Villa Floresta y desde allí hacia Villa Mitre. El centro de la ciudad y la periferia del noreste presentaron los registros intermedios y la zona costera los menores. La humedad relativa presentó los mínimos valores en el centro-este y la periferia oeste. Los intermedios en el centro y la periferia del noreste y los mayores al sur. La diferencia espacial fue de $16 \%$, la ciudad fue más húmeda que su periferia.

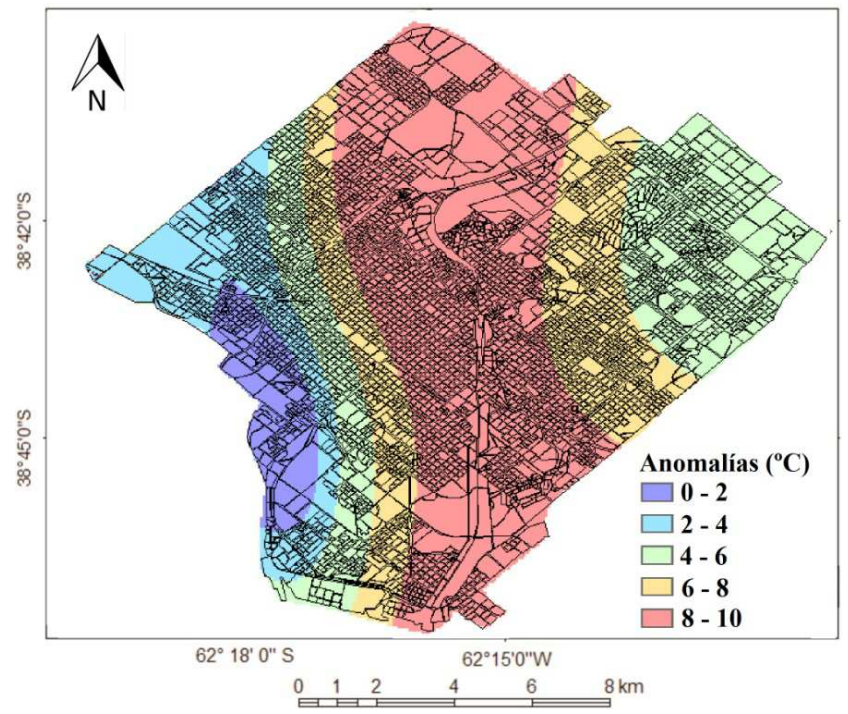

Figura 10. Anomalía de temperatura durante la ola de calor invernal.

En las olas de calor estudiadas se observó que la distribución espacial de la temperatura media del evento presentó al centro de la ciudad como el sector más cálido y los sectores de Ing. White y CONICET como los más fríos. En el verano, el centro fue más seco que su periferia. El caso contrario se analizó en el invierno. En el horario de la máxima temperatura se identificaron diferencias en el emplazamiento del área con mayores temperaturas. La zona cálida en el evento estival se extendió desde el oeste hacia el centro, mientras que en el invernal lo hizo desde el centro hacia el centro-este y sudoeste. En este momento el centro fue más húmedo durante ambos eventos.

\subsubsection{Olas de frío}

Las olas de frío provocan una alteración del ritmo térmico normal. Se considera en la literatura que las olas de frío son más peligrosas para la salud de la población, ocasionando mayor mortandad y mayor número de enfermedades infecciosas en todos los rangos etarios

Publicado en formato digital: Dr. Federico Ferrelli y Dra. María Cintia Piccolo. USO DE MEDICIONES DE ALTA FRECUENCIA PARA EL ANÁLISIS DE EVENTOS METEOROLÓGICOS URBANOS. Revista Geográfica Digital. IGUNNE. Facultad de Humanidades. UNNE. Año 14. № 27. Enero - Junio 2017. ISSN 1668-5180 Resistencia, Chaco. 
(Keatinge et al., 2000). Las olas de frío tienen un efecto perjudicial no sólo para la población sino para la agricultura, la ganadería y diversas actividades económicas (Cuadrat Pratz, et al., 2014). Si las temperaturas ambientales son extremas, los efectos sobre la salud pueden ser crónicos. Son ejemplos: enfermedades permanentes de tipo respiratorias y circulatorias (Capelli de Steffens y Piccolo, 2002; García Palomares y Alberdi, 2005). La mortalidad generada por estos eventos es mayor que la provocada por inundaciones (Kunkel et al., 1999).

A diferencia de las olas de calor, las olas de frío tienen un mayor impacto socio-ambiental. Generan la degradación de edificios, ocasionando problemas de infraestructura, aumentan la contaminación urbana, generan un mayor incremento de la utilización de energía para la calefacción, permiten el desarrollo de patologías específicas, aumentan las pérdidas en el sector agropecuario, etc. (Cuadrat et al., 2014).

En la ciudad de Bahía Blanca se registró un evento de ola de frío estival que se extendió desde el 25 al 27 de febrero de 2014. El mismo fue originado por un centro de alta presión. La temperatura media, máxima y mínimo fueron $16,1{ }^{\circ} \mathrm{C}, 26,8 \stackrel{\circ}{\circ} \mathrm{C}$ y $8,3 \stackrel{\circ}{\circ} \mathrm{C}$, respectivamente. La mayor parte del evento presentó calmas, sin embargo se registró una velocidad media del viento de $1,9 \mathrm{~km} \mathrm{~h}^{-1}$. Durante este evento se evidenció un descenso de la temperatura urbana de $4 \stackrel{\circ}{\circ}$.

El centro urbano fue más cálido pero esta vez Ing. White no fue el área más fría sino que la misma se localizó en la periferia del norte. La IICU fue de $6{ }^{\circ} \mathrm{C}$ (Figura 11). La humedad relativa presentó un mínimo en el centro de la ciudad y los máximos en la zona costera. La diferencia espacial fue $14 \%$.

En el horario de la mínima temperatura el este tuvo los mayores registros. Ing. White presentó valores elevados y las mínimas se emplazaron sobre la zona norte. La humedad relativa fue mayor en el norte y decreció en sentido norte-sudeste. La IICU fue $3,8{ }^{\circ} \mathrm{C}$ y la diferencia espacial de la humedad relativa de $17 \%$.

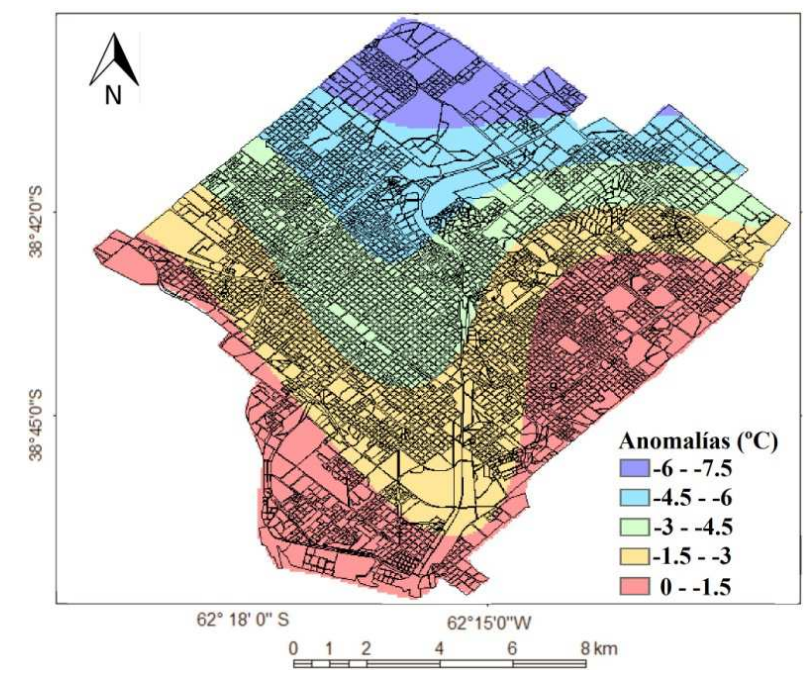

Figura 11. Anomalías térmicas durante una ola de frío estival.

Publicado en formato digital: Dr. Federico Ferrelli y Dra. María Cintia Piccolo. USO DE MEDICIONES DE ALTA FRECUENCIA PARA EL ANÁLISIS DE EVENTOS METEOROLÓGICOS URBANOS. Revista Geográfica Digital. IGUNNE. Facultad de Humanidades. UNNE. Año 14. № 27. Enero - Junio 2017. ISSN 1668-5180 Resistencia, Chaco.

En: http://hum.unne.edu.ar/revistas/geoweb/default.htm14 
Revista Geográfica Digital. IGUNNE. Facultad de Humanidades. UNNE. Año 14. № 27.

Enero - Junio 2017. ISSN 1668-5180 Resistencia, Chaco

\subsubsection{Tormentas}

La escorrentía superficial es el evento que se produce al finalizar las lluvias o chubascos. En la ciudad de Bahía Blanca existen cursos de agua, el arroyo Napostá y el Canal Maldonado, que estructuran la red de drenaje. En general el escurrimiento se da en sentido norte-sur. La ciudades modifican el escurrimiento del agua debido a la impermeabilización de la superficie y a la circulación vial (Campo et al., 2013; Zapperi, 2014).

Los mayores efectos de las lluvias torrenciales o chubascos concentrados en un período corto de tiempo se profundizan con la presencia de fuertes vientos. Ambos pueden generar inundaciones 0 anegamiento que afectan a la población (Hardoy y Pandiella, 2007). Además las lluvias intensas desencadenan procesos pluvio-hidrológicos que perturban la dinámica espacio-temporal de los ecosistemas. Estos eventos adquieren importancia dado que podrían modificar la calidad de los suelos (López Bermúdez y Romero Díaz, 1993).

La ciudad de Bahía Blanca está localizada en una región semiárida. Por lo tanto tormentas de gran intensidad en poco tiempo suelen originar inconvenientes en el tránsito, anegamiento de calles, etc. En la ciudad de Bahía Blanca el 19 de febrero de 2014 se originó una tormenta que generó una precipitación de $35,4 \mathrm{~mm}$ durante 90 minutos. Si bien ese volumen es insignificante para otras regiones del mundo, es un evento extraordinario para la ciudad. La presencia de un frente frío proveniente del sudoeste ocasionó la formación de tormentas sobre la ciudad. La velocidad media del viento fue $2,7 \mathrm{~km} \mathrm{~h}^{-1}$, con dirección NW. Antes de que comenzara el evento la temperatura era $27,9{ }^{\circ} \mathrm{C}$ y durante la precipitación se observó una reducción de la temperatura de $8,7^{\circ} \mathrm{C}$ y un incremento de la humedad relativa de 63 a $100 \%$, manteniendo este último valor hasta el final del día.

Los mayores registros de temperatura durante el evento se presentaron en el centro-este, en la zona de Villa Mitre. El centro, Villa Floresta, UOM y Corporación II tuvieron los valores intermedios y la periferia del norte y sur los menores. La IICU fue $4,1^{\circ} \mathrm{C}$. La humedad relativa media fue mayor en el noroeste, oeste y sudoeste y decreció hacia el este. Los mínimos se registraron en el centro de la ciudad. La diferencia espacial fue $16 \%$.

\subsubsection{Heladas}

Los efectos de las heladas sobre la población son similares a las condiciones de frío extremas o a las de las olas de frío. Este evento se produce en general por el ingreso de frentes fríos en los centros urbanos (Seluchi, 1992). Los efectos adversos de las heladas en las ciudades se observan mayoritariamente en el deterioro de la vegetación y en la pérdida de biomasa. Las que mayores impactos negativos producen son las heladas presentadas en las estaciones intermedias (Cogliati et al., 2006).

Se estudiaron las heladas ocurridas los días 26 y 27 de julio de 2014 en la ciudad de Bahía Blanca. La situación sinóptica que favoreció la presencia de este evento fue un centro de alta presión sobre la región (Figura 12). La helada del 26 de julio tuvo una duración de 8:30 hs y se extendió desde las 1:00 hasta las 9:30 hs. El 27 duró 11:30 hs y se extendió desde las 22:00 hs del 26 de julio hasta las 9:30 del 27 de julio. La velocidad media del viento fue de 10,6 $\mathrm{km} \mathrm{h}^{-1}$ con dirección S, SE y NW.

Publicado en formato digital: Dr. Federico Ferrelli y Dra. María Cintia Piccolo. USO DE MEDICIONES DE ALTA FRECUENCIA PARA EL ANÁLISIS DE EVENTOS METEOROLÓGICOS URBANOS. Revista Geográfica Digital. IGUNNE. Facultad de Humanidades. UNNE. Año 14. № 27. Enero - Junio 2017. ISSN 1668-5180 Resistencia, Chaco. 

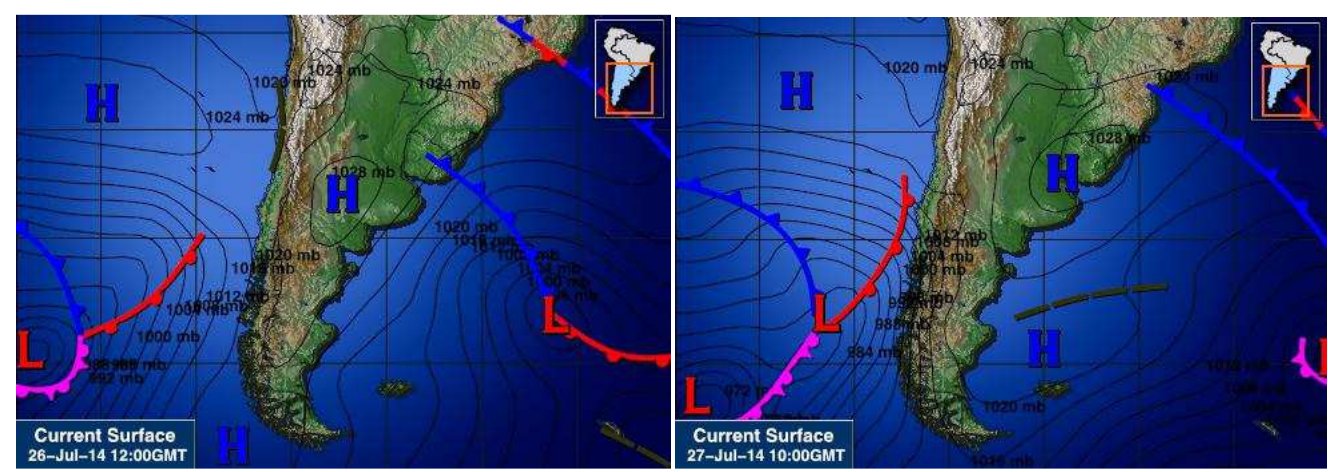

Figura 12. Situación sinóptica del día 26 y 27 de julio de 2014. Fuente: www.intellicast.com

Este evento no impactó de igual manera a toda la ciudad (Figura 13). Las heladas se observaron sólo en las zonas periféricas del norte, noroeste y noreste. Las zonas con presencia de edificios no se vieron afectados por las heladas. La misma situación se observó en la costa de Ing. White.

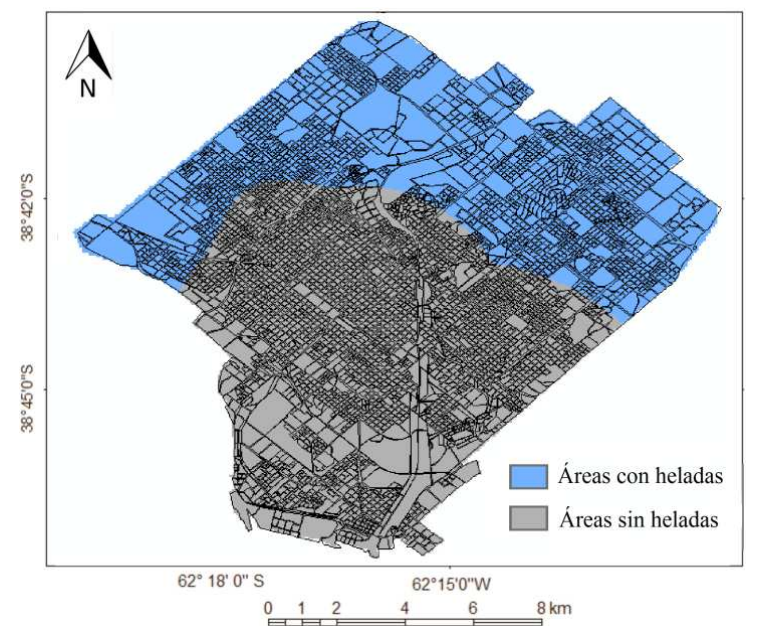

Figura 13. Áreas con presencia de heladas en la ciudad de Bahía Blanca.

\subsubsection{Nieblas}

Las nieblas son una fuente indirecta de precipitación. Estas son beneficiosas para el arbolado urbano ya que le provee de una fuente de agua (Barradas, 1983). Las nieblas urbanas se intensifican con la presencia de materiales contaminantes en el aire y por la acumulación artificial de calor de las ciudades (Albentosa Sánchez, 1979; De la Luz González, 2000). Entre los efectos sobre la población se identifican la reducción de la visibilidad y hasta la interrupción del tránsito vehicular y aéreo como consecuencia del aumento de la posibilidad de accidentes. Sumado a ello, este evento produce una reducción en la recepción de la radiación solar (De la Luz González, 2000).

En la ciudad de Bahía Blanca durante el período de estudio se presentaron nieblas los días 5 y 6 de julio de 2014. Durante el evento se observó el paso de un frente que generó la

Publicado en formato digital: Dr. Federico Ferrelli y Dra. María Cintia Piccolo. USO DE MEDICIONES DE ALTA FRECUENCIA PARA EL ANÁLISIS DE EVENTOS METEOROLÓGICOS URBANOS. Revista Geográfica Digital. IGUNNE. Facultad de Humanidades. UNNE. Año 14. № 27. Enero - Junio 2017. ISSN 1668-5180 Resistencia, Chaco. 
formación de nubes y un centro de baja presión sobre la costa de la provincia de Buenos Aires. Esta situación generó el pasaje de vientos débiles y húmedos del sector sur favoreciendo la formación de nubosidad y nieblas. Este evento tuvo una duración de 23 horas y se manifestó desde las 6:30 hs del 5 de julio hasta las 5:30 del 6 de julio. La velocidad media del viento fue de $10 \mathrm{~km} \mathrm{~h}^{-1}$ con dirección del S, SW y SE y la presión atmosférica fue normal (1012,8 hPa).

Al tratarse de una situación de viento sur, las nieblas se presentaron en la zona de Ing. White y en la periferia norte, noroeste y oeste. La abundancia de vegetación y la presencia de terrenos al descubierto favorecieron la formación de niebla. La situación opuesta se presentó en las zonas edificadas, en ellas la humedad relativa media fue de $86 \%$ y no se generaron nieblas (Figura 14).

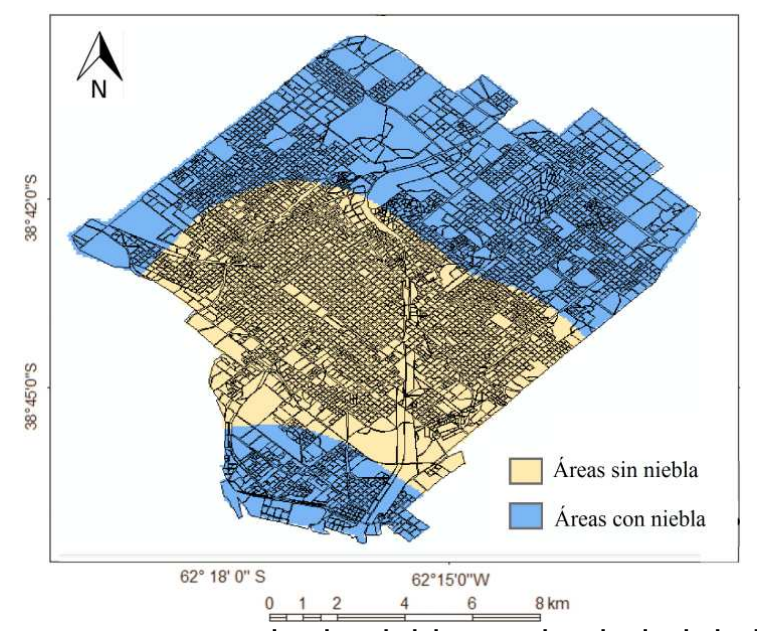

Figura 14. Áreas con presencia de nieblas en la ciudad de Bahía Blanca.

\subsection{Escala micro-local}

Las variaciones en la temperatura y la humedad relativa en cada evento fueron distintas según los barrios de la ciudad debido a las condiciones de sitio. El análisis de los impactos de los eventos meteorológicos a escala micro-local se realizó considerando el valor de temperatura y humedad relativa media mensual y diaria (del día anterior y posterior al evento) en relación con el valor medio calculado para cada evento estudiado. Esto permitió analizar las fluctuaciones térmicas y húmedas micro-locales que se originaron durante los distintos eventos meteorológicos.

Cuando se registraron los vientos del norte, las anomalías térmicas oscilaron entre $8{ }^{\circ} \mathrm{C}$ (Bella Vista) y 1,4 ${ }^{\circ} \mathrm{C}$ (Ing. White) (Figura 15). Durante las olas de calor de invierno y verano se registraron anomalías similares en CONICET $\left(5,7^{\circ} \mathrm{O}\right)$ y Centro $\left(6,7^{\circ} \mathrm{\circ}\right)$. En el invierno, los mayores valores de temperatura se midieron en UOM, Villa Mitre, Bella Vista y Patagonia, mientras que Villa Floresta, Ing. White, Noroeste y Cooperación II lo hicieron en verano. La mayor diferencia en el verano fue $9,1^{\circ} \mathrm{C}$ (Noroeste) y la menor de 5,7 ${ }^{\circ} \mathrm{C}$ (CONICET), mientras que en el invierno el valor más elevado fue de $8,5^{\circ} \mathrm{C}$ (Villa Mitre) y el menor de $2,1^{\circ} \mathrm{C}$ (Cooperación II) (Figura 15).

Publicado en formato digital: Dr. Federico Ferrelli y Dra. María Cintia Piccolo. USO DE MEDICIONES DE ALTA FRECUENCIA PARA EL ANÁLISIS DE EVENTOS METEOROLÓGICOS URBANOS. Revista Geográfica Digital. IGUNNE. Facultad de Humanidades. UNNE. Año 14. № 27. Enero - Junio 2017. ISSN 1668-5180 Resistencia, Chaco.

En: http://hum.unne.edu.ar/revistas/geoweb/default.htm17 
Revista Geográfica Digital. IGUNNE. Facultad de Humanidades. UNNE. Año 14. № 27. Enero - Junio 2017. ISSN 1668-5180 Resistencia, Chaco

Durante la ola de frío la ciudad temperatura en la ciudad descendió $5 \stackrel{\circ}{ } \mathrm{C}$ en relación con su valor medio mensual. El menor valor fue $-7,5 \stackrel{\circ}{ } \mathrm{C}$ en Bella Vista y el mayor $-5,1^{\circ} \mathrm{C}$ en Patagonia. Cooperación II, Ing. White, Villa Floresta y Bella Vista presentaron valores medios inferiores a $5 \stackrel{\circ}{ } \mathrm{C}$ con $-7,7,-5,8,-5,6$ y $-5,2 \stackrel{\circ}{\circ}$, respectivamente. El resto de la ciudad registró valores mayores a este umbral. Las zonas que presentaron menores diferencias fueron CONICET y Villa Mitre con $-3,5^{\circ} \mathrm{C}$ (Figura 15).

La amplitud térmica entre la temperatura media mensual y la calculada durante el evento de heladas fue más intensa en la periferia (CONICET, $-11,4^{\circ} \mathrm{C}$ ) y en la de los barrios residenciales (UOM, $-11,3^{\circ} \mathrm{C}$ y Cooperación, $\left.-11,2^{\circ} \mathrm{C}\right)$. Las menores diferencias se observaron en Patagonia y Villa Mitre con $-5,5$ y $-5,6 \stackrel{\circ}{ } \mathrm{C}$, respectivamente. Finalmente, los chubascos y las nieblas hicieron que la temperatura urbana descienda $10 \stackrel{\circ}{ } \mathrm{C}$ (teniendo en cuenta como umbral la temperatura media mensual) (Figura 15).

Cuando se analizan las anomalías en una escala diaria se observan diferencias notables. El día anterior a la presencia de vientos del norte descendieron la temperatura $3,9 \stackrel{\circ}{ } \mathrm{C}$, es decir que el viento aumentó la temperatura urbana. El mayor valor se registró en Bella Vista, localizada en el centro-noreste de la ciudad. Esta presentó una anomalía de 5,6 ํㅡ mayor durante este evento. El menor impacto se observó en Ing. White, localizada al sur con 2,5 ${ }^{\circ} \mathrm{C}$. Los vientos del sur hicieron que la ciudad se enfríe $3,5^{\circ} \mathrm{C}$ en relación al día anterior. Esta anomalía fue $-4,5^{\circ} \mathrm{C}$ en Cooperación II y $-2 \stackrel{\circ}{\circ} \mathrm{C}$ en Villa Mitre (Figura 15).

Las olas de calor presentaron mayores diferencias en el verano que en el invierno. En el verano la temperatura urbana fue $8,2{ }^{\circ} \mathrm{C}$ mayor que el valor medio registrado el día anterior al evento. El mayor efecto se presentó en Villa Floresta y UOM con 10,4 y $10,1{ }^{\circ} \mathrm{C}$, respectivamente y el menor en Patagonia con $6 \stackrel{\circ}{\circ} \mathrm{C}$. El evento de invierno aumentó $3,8 \stackrel{\circ}{\circ} \mathrm{C}$ la temperatura urbana con respecto a la media del día anterior. La mayor diferencia se observó en

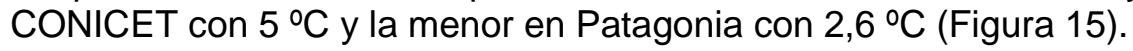

La ola de frío de verano originó un descenso de $4{ }^{\circ} \mathrm{C}$ en la ciudad. La mayor amplitud se midió en CONICET con $-8{ }^{\circ} \mathrm{C}$. Ing. White manifestó las menores diferencias $\left(-2,6{ }^{\circ} \mathrm{C}\right)$. Durante las heladas, chubascos y nieblas se presentó una diferencia negativa en toda la ciudad. Esta fue mayor durante los chubascos $\left(-5,9^{\circ} \mathrm{C}\right)$, intermedia en las heladas $\left(-4,7^{\circ} \mathrm{C}\right)$ y menor en las nieblas $(-1,4 \stackrel{\circ}{\circ})$ (Figura 15).

La relación entre el valor medio del evento con el del día posterior al mismo permitió afirmar que tanto los vientos del norte como las olas de calor son los eventos permitieron un aumento de la temperatura de la ciudad. En el resto de los eventos la temperatura disminuyó. Las mayores amplitudes se observaron durante los chubascos. La temperatura urbana descendió $8 \stackrel{\circ}{\circ}$ durante un chubasco, $3,3 \stackrel{\circ}{C}$ durante una helada y 1,7 durante las nieblas (Figura 15).

Publicado en formato digital: Dr. Federico Ferrelli y Dra. María Cintia Piccolo. USO DE MEDICIONES DE ALTA FRECUENCIA PARA EL ANÁLISIS DE EVENTOS METEOROLÓGICOS URBANOS. Revista Geográfica Digital. IGUNNE. Facultad de Humanidades. UNNE. Año 14. № 27. Enero - Junio 2017. ISSN 1668-5180 Resistencia, Chaco.

En: http://hum.unne.edu.ar/revistas/geoweb/default.htm18 

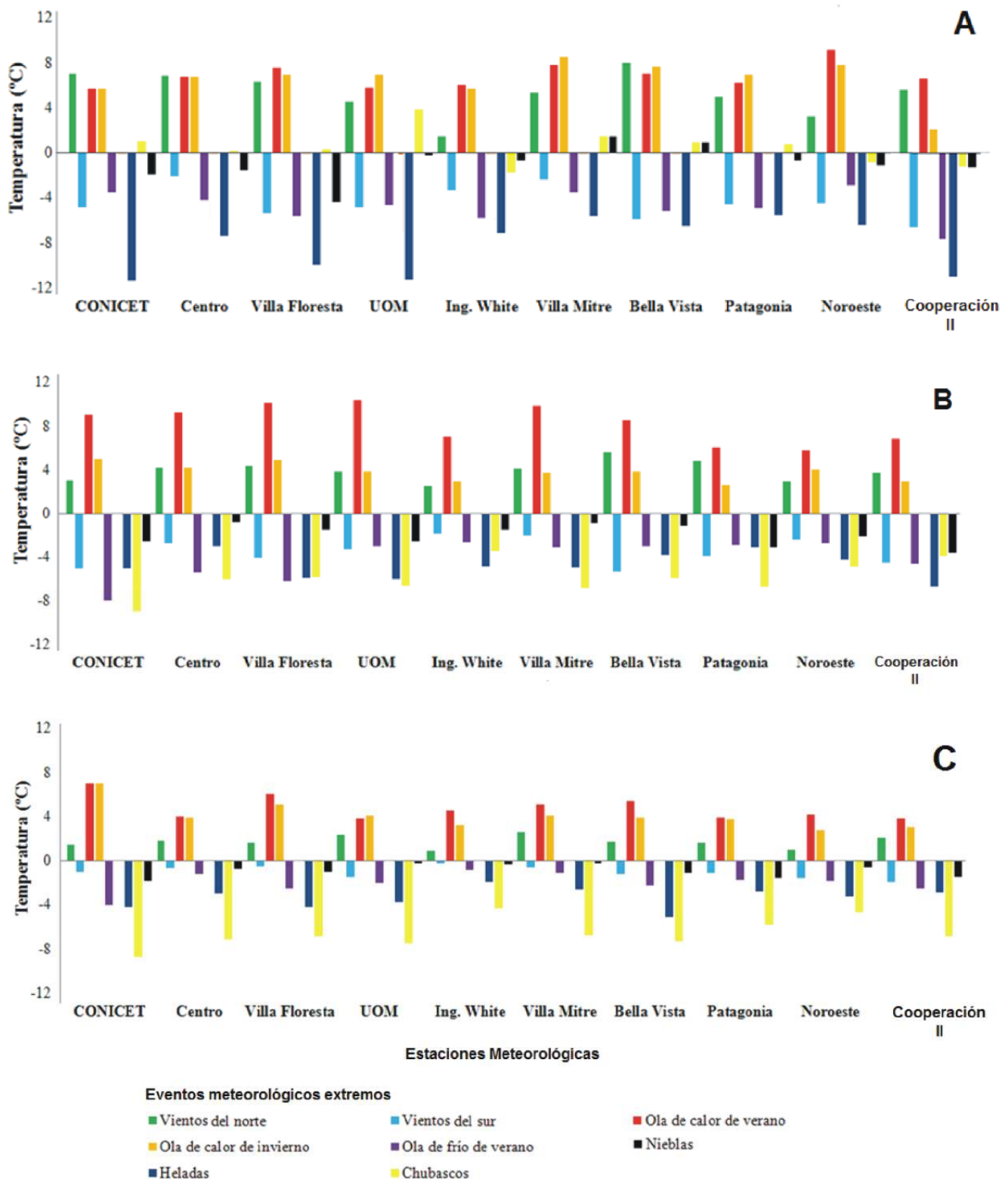

Figura 15. Anomalía entre: A. Temperatura media mensual, B. Temperatura media del día anterior, C. Temperatura media del día posterior y la registrada durante distintos eventos meteorológicos.

En lo referente a la humedad relativa media mensual y su relación con la media del evento, se observó un incremento de la misma durante vientos del sur, heladas, chubascos y nieblas. Los vientos del norte generaron un tiempo más seco en la ciudad, exceptuando la zona

Publicado en formato digital: Dr. Federico Ferrelli y Dra. María Cintia Piccolo. USO DE MEDICIONES DE ALTA FRECUENCIA PARA EL ANÁLISIS DE EVENTOS METEOROLÓGICOS URBANOS. Revista Geográfica Digital. IGUNNE. Facultad de Humanidades. UNNE. Año 14. № 27. Enero - Junio 2017. ISSN 1668-5180 Resistencia, Chaco.

En: http://hum.unne.edu.ar/revistas/geoweb/default.htm19 
portuaria. La ola de calor de verano generó una situación húmeda en los vecindarios de CONICET (2\%) y Noroeste ( $1 \%$ ) y una seca en el resto de la ciudad (Figura 16).

La relación entre las medias del evento con las del día anterior presentó anomalías negativas durante los vientos del norte. En dicho evento la humedad relativa descendió $9 \%$. La mayor anomalía se observó en Villa Floresta (-14\%) y la menor en Ing. White (-2 \%). La ola de calor de invierno presentó el mismo patrón. Toda la ciudad, exceptuando CONICET (9\%), presentó valores negativos (5\% más seca) (Figura 16).

Durante los vientos del sur, la ciudad fue $19 \%$ más húmeda que el día anterior. El mayor registro fue en Villa Floresta (26\%) y el menor en Bella Vista (12\%). Las olas de frío y la de calor favorecieron un aumento de la humedad relativa en la ciudad con respecto a la del día anterior al evento con diferencias de 13,16 y $6 \%$, respectivamente. Las heladas y las nieblas dieron lugar a una situación similar con valores de 17 y $25 \%$, respectivamente. Naturalmente, los chubascos fueron los que incrementaron la humedad relativa (36\%). Los valores más elevados se calcularon en Patagonia (41\%), Bella Vista (39\%) y Villa Mitre (24\%) (Figura 16).

En relación con los valores medios del día posterior se observaron valores negativos sólo durante los vientos del norte $(-7 \%)$. El resto de los eventos manifestaron anomalías medias positivas. La ciudad fue más húmeda durante las heladas (24\%), las nieblas (26\%) y los chubascos $(28 \%)$. Presentó valores intermedios en las olas de frío de verano (10\%) e invierno $(13 \%)$ y con vientos del sur (14\%) y los menores en la ola de calor de verano (5\%) (Figura $16)$.

Publicado en formato digital: Dr. Federico Ferrelli y Dra. María Cintia Piccolo. USO DE MEDICIONES DE ALTA FRECUENCIA PARA EL ANÁLISIS DE EVENTOS METEOROLÓGICOS URBANOS. Revista Geográfica Digital. IGUNNE. Facultad de Humanidades. UNNE. Año 14. № 27. Enero - Junio 2017. ISSN 1668-5180 Resistencia, Chaco.

En: http://hum.unne.edu.ar/revistas/geoweb/default.htm20 

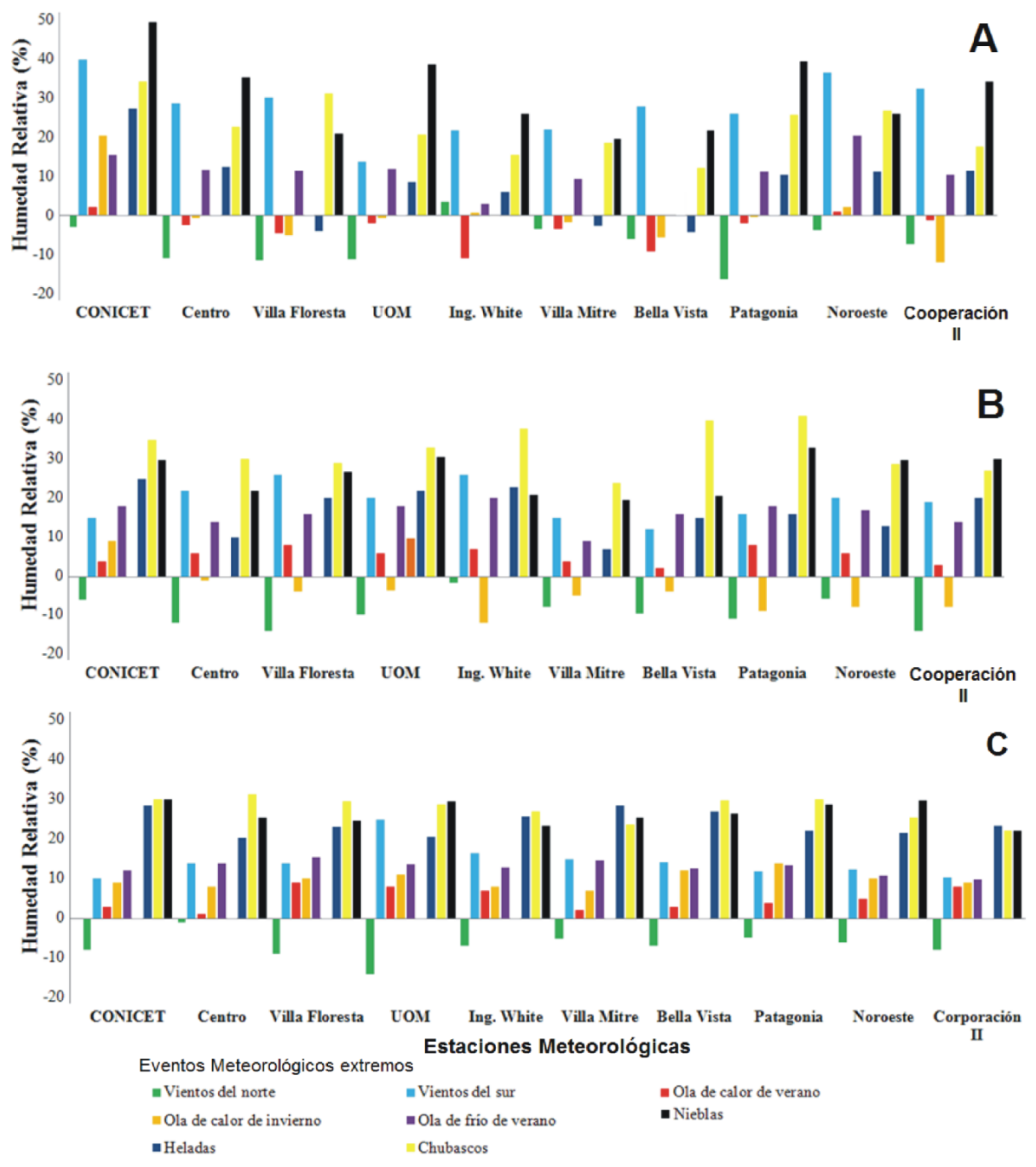

Figura 16. Anomalía entre: A. Humedad relativa media mensual, B. Humedad relativa media del día anterior, C. Humedad relativa media del día posterior y la registrada durante distintos eventos meteorológicos.

\section{Conclusiones}

Los eventos meteorológicos urbanos analizados en este trabajo permitieron identificar distintas respuestas de la temperatura y la humedad relativa en los diferentes vecindarios de Bahía Blanca. Los vientos del norte incrementaron la temperatura urbana y disminuyeron la humedad relativa. La zona cálida de la ciudad está orientada en la dirección del viento norte. Los vientos del sur fueron fríos y húmedos. Los mismos redujeron la temperatura e

Publicado en formato digital: Dr. Federico Ferrelli y Dra. María Cintia Piccolo. USO DE MEDICIONES DE ALTA FRECUENCIA PARA EL ANÁLISIS DE EVENTOS METEOROLÓGICOS URBANOS. Revista Geográfica Digital. IGUNNE. Facultad de Humanidades. UNNE. Año 14. № 27. Enero - Junio 2017. ISSN 1668-5180 Resistencia, Chaco.

En: http://hum.unne.edu.ar/revistas/geoweb/default.htm21 
Revista Geográfica Digital. IGUNNE. Facultad de Humanidades. UNNE. Año 14. № 27.

Enero - Junio 2017. ISSN 1668-5180 Resistencia, Chaco

incrementaron la humedad. El efecto de la dirección del viento se observó en la distribución espacial de la humedad relativa. Los mayores valores se observaron en el sur y decrecieron hacia el norte de la ciudad. Se observaron durante ambos eventos efectos de isla de calor urbana a pesar de superar la velocidad crítica del viento. Esto se debe a que los edificios del centro de la ciudad presentan una situación de barrera que disminuyen los vientos e impiden que se disipe el calor.

El análisis micro-local de los eventos extremos evidenció diferencias al cambiar el umbral de análisis. Al compararlo con la media mensual, se observó que la temperatura del aire fue mayor con los vientos del norte y las olas de calor y menor en el resto de los eventos. En lo referente a las medias diarias posterior y anterior, los vientos del norte, del sur y la ola de frío no presentaron diferencias significativas. En cambio, sí se observaron durante los chubascos y las olas de calor. La humedad relativa fue menor cuando sopló el viento del norte. Con respecto a la media estacional se observó una disminución durante las olas de calor y la ola de frío de verano. Los valores medios de los días posteriores y anteriores permitieron establecer que los chubascos fueron los que más impactaron sobre la humedad ya que presentaron a la ciudad aproximadamente un $28 \%$ más húmeda. Las heladas, las nieblas, las olas de frío y los vientos del sur presentaron un comportamiento similar registrando amplitudes mensuales y diarias superiores al $15 \%$.

Se estudiaron los efectos de distintos eventos meteorológicos sobre la ciudad de Bahía Blanca. Los mismos permitieron analizar sus impactos sobre los distintos sectores de la ciudad. La importancia de estudiarlos con mediciones en alta frecuencia recae en establecer las sectores que son más vulnerables ante la presencia los distintos eventos meteorológicos. Por todo el análisis realizado, se considera que el conocimiento y análisis de estos eventos a distintas escalas espaciales de análisis son importantes para la generación de información que servirá de base para la propuesta de un manejo del espacio urbano. El impacto de los mismos es diferente en cada sector de la ciudad por lo que es necesario tomar medidas que se adapten a las condiciones de sitio de cada uno de los espacios urbanos analizados.

\section{Agradecimientos}

Los autores desean agradecer al Consejo Nacional de Investigaciones Científicas y Técnicas (CONICET, Argentina), a la Universidad Nacional del Sur (UNS, Argentina) y al InterAmerican Institute for Global Change Research (IAI) CRN3038, el cual es apoyado por la US National Science Foundation (Grant GEO-1128040) por el financiamiento total de la presente investigación.

\section{Referencias}

Alberdi J.C., Díaz J., Montero J.C., Mirón I.J. 1998. Daily mortality in Madrid Community (Spain) 1986-1991: relationship with atmospheric variable. Eur. J. Epidemiol., 14:571-578.

Albentosa Sánchez, L. M. 1979. Contaminación atmosférica y nieblas en las áreas urbanas industrializadas. Acta Geológica Hispánica, 14:529-533.

Publicado en formato digital: Dr. Federico Ferrelli y Dra. María Cintia Piccolo. USO DE MEDICIONES DE ALTA FRECUENCIA PARA EL ANÁLISIS DE EVENTOS METEOROLÓGICOS URBANOS. Revista Geográfica Digital. IGUNNE. Facultad de Humanidades. UNNE. Año 14. № 27. Enero - Junio 2017. ISSN 1668-5180 Resistencia, Chaco.

En: http://hum.unne.edu.ar/revistas/geoweb/default.htm22 
Barton, E.D., Lavín, M.F., Trasviña, A. 2009. Coastal circulation and hydrography in the Gulf of Tehuantepec, Mexico, during winter. Continental Shelf Research, 29:485-500.

Barradas, V. L. 1983. Capacidad de captación de agua a partir de la niebla en Pinus Montezumae Lambert, de la región de las grandes montañas del estado de Veracruz. Biotica, 8 (4):427-431.

Campo, A. M., Zapperi, P. A., Piccone, N. 2013. Precipitation and rainwater pH spatial distribution in Bahía Blanca and Tandil, Argentina. Journal of Earth Science and Engineering, 3:683-389.

Capelli de Steffens, A., Piccolo, M.C., Hernández González, H., Navarrette, G., Lara R. 1997. La isla de calor en Temuco, Chile: Situación invernal. Revista Geofísica, IPGH (México), 46: 5-16.

Capelli de Steffens, A., Piccolo, M.C., Hernández González, H., Navarrette, G., Lara R. 2001. La isla de calor estival en Temuco. Papeles de Geografía, 33: 49-60.

Capelli de Steffens, A., Piccolo, M.C. 2002. Monthly mortality changes related temperature in Bahía Blanca, Argentina. GEOACTA, 27: 62-70.

Capelli de Steffens, A., Piccolo, M. C., Campo de Ferrera, A. 2005. Clima urbano de Bahía Blanca. Editorial Dunken, $199 \mathrm{p}$.

Cogliati, M. G.; Britos, P., García Martínez, R. 2006. Análisis de variables agrometeorológicas en noches de heladas utilizando mapas autoorganizados $y$ algoritmos de inducción. XI Reunión Argentina de Agrometeorología, Universidad de La Plata, Argentina, p. 121-123.

Cony, M., Hernández, E., Del Teso, T. 2008. Influence of synoptic scale in the generation of extremely cold days in Europe. Atmósfera, 21: 389-401.

Cony, M., Martín, L., Hernández, E., Del Teso, T. 2010. Synoptic patterns that contribute to extremely hot days in Europe. Atmósfera, 23: 295-306.

Coronel, A., Feldman, S., Piacentini, R. 2014. Efecto de agricultura y forestación urbana y peri-urbana sobre la mitigación y adaptación al cambio climático: impactos sobre la temperatura. Universidad Nacional de Rosario. Facultad de Ciencias Agrarias, p. 33.

Correa, E.N., Flores Larsen, S., Lesino, G. 2003. Isla de Calor Urbana: Efecto de los Pavimentos. Informe de Avance. Avances en Energías Renovables y Medio Ambiente, 7(2): 11.25-11.30.

Cuadrat, J.M., Saz, M.A., Serrano, R., Tejedor E. 2014. El clima del término municipal de Zaragoza en el contexto del cambio global. Departamento de Geografía y Ordenación del Territorio, Universidad de Zaragoza, España, p. 57.

De la Luz González, G. 2000. Calidad del aire en las principales ciudades de México. Instituto Nacional de Ecología, México, p. 13.

Díaz, J., García, R., Prieto, L., Linares, C., López, C. 2005. Mortality impact of extreme winter temperatures. International Journal of Biometeorology, 49:178- 183.

Publicado en formato digital: Dr. Federico Ferrelli y Dra. María Cintia Piccolo. USO DE MEDICIONES DE ALTA FRECUENCIA PARA EL ANÁLISIS DE EVENTOS METEOROLÓGICOS URBANOS. Revista Geográfica Digital. IGUNNE. Facultad de Humanidades. UNNE. Año 14. № 27. Enero - Junio 2017. ISSN 1668-5180 Resistencia, Chaco. 
Fuentes Pérez, C. A. 2014. Islas de Calor Urbano en Tampico, México. Impacto del microclima a la calidad del hábitat. Nova Scientia, 7: 495-515.

García, M. C. 2014. Escenario de riesgo climático por tormentas severas y granizadas en Mar del Plata y Necochea-Quequén, Argentina. Revista Brasileira de Climatología, 14: 39-49.

García Palomares, J. C., Alberdi, J. C. 2005. Mortalidad en la ciudad de Madrid durante la ola de calor del verano de 2003. GeoFocus: Revista Internacional de Ciencia y Tecnología de la Información Geográfica, 5:19-39.

García-Pina, R., Garcés, A. T., Sanz Navarro, J., Navarro Sánchez, C., García-Fulgueiras A. 2008. Efecto del calor sobre el número de urgencias hospitalarias en la región de Murcia durante los veranos del período 2000-2005 y su uso en la vigilancia epidemiológica. Rev. Esp. Salud Pública, 82, 153-166.

Keatinge, W.R., Donaldson, G.C., Cordioli, E., Martinelli, M., Kunst, A.E., Mackenbach, J.P., Nayha, S., Vuori,I. 2000. Heat related mortality in warm and cold regions of Europe: observational study. BMJ, 321 (7262):670-673.

Kunkel, K., Pielke, R., Changnon, S.A. 1999. Temporal fluctuations in weather and climate extremes that cause economic and human impacts: a review. Bulletin of the American Meteorological Society, 80: 1077-1098

Hardoy J., Pandiella, G. 2007. Adaptación de las ciudades argentinas a los efectos del cambio y la variabilidad climática. Medio Ambiente y Urbanización, 67 (1): 45-48.

INDEC, 2011. Instituto Nacional de Estadística y Censos. Disponible en: http://www.censo2010.indec.gov.ar/ (fecha de acceso: 20 de mayo de 2011).

Llanque Chana, J. 2003. Efectos de la contaminación atmosférica en el clima urbano y calidad ambiental de Arequipa. Cuadernos de Investigación Urbanística, 37: 95-106.

López Bermúdez F., Romero Díaz, M. A. 1993. Génesis y consecuencias erosivas de las lluvias de alta intensidad en la región mediterránea. Cuadernos de Investigación Geográfica:18-19, 7-28.

Müller, G. V. 2005. Variabilidad inter-anual de las heladas en la Pampa Húmeda. Revista Brasileira de Climatología, 1:141-152.

OMM, 1992. Organización Meteorológica Mundial. Vocabulario Meteorológico Internacional. Secretaría de la OMM, Segunda Edición, p. 461.

Piccolo, M.C., Capelli de Steffens, A. 1985. Clima urbano bahiense: Una experiencia de verano. Contribuciones Científicas de la Sociedad Argentina de Estudios Geográficos, 2:382396.

Oke, T. R. 1973. City size and the urban heat island. Atmospheric Environment, 7:769-779.

Oke, T. R., Hannel, F.G. 1970. The form of the urban heat island in Hamilton, Canada. Urban Climatology. World Meteorol. Org. Tech., 108:113-126.

Publicado en formato digital: Dr. Federico Ferrelli y Dra. María Cintia Piccolo. USO DE MEDICIONES DE ALTA FRECUENCIA PARA EL ANÁLISIS DE EVENTOS METEOROLÓGICOS URBANOS. Revista Geográfica Digital. IGUNNE. Facultad de Humanidades. UNNE. Año 14. № 27. Enero - Junio 2017. ISSN 1668-5180 Resistencia, Chaco. 
Pejenaute Goñi, J. 2006. Las nieblas y el tráfico aéreo en el aeropuerto de Pamplona. Comunicación presentada al $\mathrm{V}$ Congreso Internacional de la AEC, España. Disponible en: http://www.divulgameteo.es/ampliab/4/459/Las-nieblas-y-el-trafico-aereo-en-el-aeropuerto-dePamplona.html (fecha de acceso: 8 de abril de 2016).

Prieto, L., García Herrera, R', Díaz, J., Hernández, E., Del Teso, T. 2004. Minimum extreme temperatures over Peninsular Spain. Global and Planetary Change, 44:59-71.

Reguero, B. G., Losada, I. J., Méndez, F.J., 2015. Las ciudades portuarias ante un clima cambiante. Dossier, 20-25.

Santiago Lastra J.A., López Carmona, M., López Mendoza, S. 2008. Tendencias del cambio climático global y los eventos extremos asociados. Revista de Sociedad, Cultura y Desarrollo Sustentable, 4 (3):625-633.

Seluchi, M. E. 1992. Condiciones meteorológicas asociadas a la ocurrencia de heladas en la región de Maringá. Revista Brasileira de Meteorología, 7 (1):523-534.

Servicio Meteorológico Nacional (SMN, Argentina) disponible en: www.smn.gov.ar/ (fecha de acceso octubre 2013-mayo 2016).

Stewart, I.D. y Oke, T.R., 2012. Local climate zones for urban temperature studies. Bulletin of the American Meteorological Society, 93 (12):1879-1900.

Szegedi, S., Kircsi, A. 2003. The development of the urban heat island under various weather conditions in Debrecen, Hungary. University of Debrecen, Hungary, p. 6.

Villamil Cajoto, I., Díaz Peromingo, J.A., Villacian Vicedo, G., Sánchez Leira, J., García Suarez, F., Saborido Froján, J., Iglesias Gallego, M. 2005. Impacto de la ola de calor de 2003 en el hospital de Riveira (A Coruña). Anales de Medicina Interna, 22: 15-20.

Zapperi, P.A. 2014. Caracterización del escurrimiento de Bahía Blanca. Revista Universitaria de Geografía, 23 (1-2):125-150.

Publicado en formato digital: Dr. Federico Ferrelli y Dra. María Cintia Piccolo. USO DE MEDICIONES DE ALTA FRECUENCIA PARA EL ANÁLISIS DE EVENTOS METEOROLÓGICOS URBANOS. Revista Geográfica Digital. IGUNNE. Facultad de Humanidades. UNNE. Año 14. № 27. Enero - Junio 2017. ISSN 1668-5180 Resistencia, Chaco.

En: http://hum.unne.edu.ar/revistas/geoweb/default.htm25 